\title{
Peptide-Based Nanovaccines in the Treatment of Cervical Cancer: A Review of Recent Advances
}

\author{
Jiahui Zhang',*, Jingyi Fan',*, Mariusz Skwarczynski', Rachel J Stephenson', Istvan Toth ${ }^{1-3}$, \\ Waleed M Hussein (iD)
}

'School of Chemistry and Molecular Biosciences, The University of Queensland, St Lucia, QLD, Australia; ${ }^{2}$ School of Pharmacy, The University of Queensland, Woolloongabba, QLD, Australia; ${ }^{3}$ Institute for Molecular Biosciences, The University of Queensland, St Lucia, QLD, Australia

*These authors contributed equally to this work

Correspondence: Waleed M Hussein, School of Chemistry and Molecular Biosciences, The University of Queensland, St Lucia, QLD, 4072, Australia, Tel +6I 73365 2782, Email w.hussein@uq.edu.au

\begin{abstract}
Persistent infection with high-risk human papillomaviruses (HPVs), such as HPV-16 and HPV-18, can induce cervical cancer in humans. The disease carries high morbidity and mortality among females worldwide. Inoculation with prophylactic HPV vaccines, such as Gardasil ${ }^{\circledR}$ or Cervarix ${ }^{\circledR}$, is the predominant method of preventing cervical cancer in females 6 to 26 years of age. However, despite the availability of commercial prophylactic HPV vaccines, no therapeutic HPV vaccines to eliminate existing HPV infections have been approved. Peptide-based vaccines, which form one of the most potent vaccine platforms, have been broadly investigated to overcome this shortcoming. Peptide-based vaccines are especially effective in inducing cellular immune responses and eradicating tumor cells when combined with nanoscale adjuvant particles and delivery systems. This review summarizes progress in the development of peptide-based nanovaccines against HPV infection.
\end{abstract}

Keywords: human papillomavirus, cervical cancer, peptide-based vaccines, nanovaccine

\section{Introduction}

Cervical cancer is a malignant tumor formed in the stem of the uterus. ${ }^{1}$ Human papillomavirus (HPV) is a pathogen that causes fatal cervical cancer and related cancerous diseases; it has been detected in $99.7 \%$ of all cervical cancers. ${ }^{2}$ Two viral proteins, E6 and E7, are pivotal in triggering infected cells to undergo oncogenesis with uncontrolled proliferation, unrestricted telomerase activity, and subsequently cervical cancer growth. ${ }^{3}$ HPV infection can cause cancer in the cervix, but also in the vagina, vulva, penis, and oropharynx. ${ }^{1}$ Typically, the cervix comprises squamous cells on the outer layer and columnar gland cells on the inner side. Carcinogenesis mainly occurs at the junction of these two cell types, forming squamous cell carcinoma ( $>90 \%$ ) or adenocarcinoma. ${ }^{4,5}$ Specifically, the initial infection may cause dysplasia, namely, cervical intraepithelial neoplasia (CIN) or adenocarcinoma, in situ. If the infection persists and cannot be cleared by the body's immune system, it leads to an invasive cancer. ${ }^{5}$

The treatment of cervical cancer depends on how developed the cancer is: from cervical carcinoma in situ to stages IIV. Primary treatments for cervical cancer include surgery, radiation therapy and/or chemotherapy. For early or smallscale carcinoma, surgery and radiation therapy can virtually eradicate cell infection and achieve recovery. For cervical cancer stages IB and IIA, interventional chemotherapy is often required for co-treatment. Commonly used chemotherapy drugs include cisplatin, carboplatin, paclitaxel $\left(\operatorname{Taxol}^{\circledR}\right)$, and topotecan. ${ }^{5}$ Unfortunately, radiation and chemotherapy often cause many side effects due to their limited targeting affinity towards tumor cells. Vaccination against HPV infection and cervical cancer offers a promising new treatment option without the risk of significant adverse effects. ${ }^{6}$

Traditional vaccines have been based on live-attenuated or killed microorganisms derived from pathogenic viruses or bacteria, which directly trigger the immune system to secrete neutralizing antibodies against pathogenic antigens. ${ }^{6-8}$ Importantly, currently available HPV prophylactic subunit vaccines, which induce antibody-based responses, cannot be 
used for effective cancer eradication. ${ }^{9,10}$ Fortunately, new vaccines targeting cellular immune responses are being developed and can be applied for cancer treatment. ${ }^{10-12}$ However, the use of cancer cell homogenates or cancerassociated proteins is associated with a risk of inducing autoimmune responses. Therefore, peptide-based antigens are being extensively assessed in cancer vaccine designs: several of these vaccines have reached Phase III clinical trials. ${ }^{13,14}$

As an effective vaccine candidate platform, peptide-based vaccines have the potential to induce cellular immune responses and eliminate cervical cancer using non-autoimmunogenic antigen sequences derived from cancer-associated proteins. Peptide-based vaccines typically have increased stability during storage and transport, and they can be rapidly obtained through a convenient and straightforward preparation method. ${ }^{15}$ Nevertheless, the low immunogenicity of peptide-based vaccines and poor stability in vivo have been primary drawbacks. One of the most promising strategies to overcome these problems is the introduction of nanosized delivery systems and adjuvants (immune stimulants) to generate so-called nanovaccines. ${ }^{16,17}$ Nanoparticles mediate the stimulatory effect on the immune system through their particle properties, such as size, charge, hydrophobicity, and surface-anchored targeting moieties. ${ }^{18}$ Optimized nanoparticles can more effectively deliver bound antigen to antigen presenting cells (APCs), thereby triggering a durable and efficient immune response. ${ }^{17}$

This review details the current global burden of cervical cancer, mechanisms of HPV infection, associated cancer formation, and immune reactions. It also summarizes recent advances in therapeutic peptide-based vaccines against cervical cancer, including the identification of major HPV vaccine antigens and epitopes, and appropriate vaccine delivery systems and adjuvants. There is a strong focus on HPV peptide-based nanovaccines. Finally, we highlight the most recent progress of preclinical and human trials of HPV peptide-based nanovaccines.

\section{Disease Burden and Current Prophylactic Vaccines Against Cervical Cancer}

Cervical cancer is a primary public health problem. The disease has the fourth-highest reported cancer incidence in females worldwide, ranking only after breast, colorectal, and lung cancers. ${ }^{19,20}$ According to recent statistics from the World Health Organization, there was an estimated 569,847 cases of cervical cancer and 311,365 deaths in 2018; cervical cancer accounted for approximately $7.5 \%$ of all female cancer deaths globally. ${ }^{21,22}$ The age-standardized prevalence of cervical cancer was around 13.1 per 100,000 females worldwide, although there were significant differences between countries. ${ }^{20}$ The global average age at diagnosis and death of cervical cancer patients was approximately 53 years and 59 years, respectively. ${ }^{20}$ It has been projected that cervical cancer will lead to more than 443,000 deaths annually by 2030 , with the majority of these expected in sub-Saharan Africa. ${ }^{23}$

Over the past 30 years, the incidence of cervical cancer in high-income nations has been half of that of low-income countries due to accurate cervical screening initiatives, effective cancer treatments, and broad availability of prophylactic HPV vaccines. ${ }^{24}$ In 2020 alone, the mortality rate of cervical cancer across all 78 low- and middle-income countries was around 13.2 per 100,000 women. ${ }^{24}$ Cervical cancer-related deaths primarily occurred in eastern, western, middle, and southern Africa, with the highest rates recorded in Eswatini. ${ }^{20}$ It has been estimated that cervical cancer cases and associated mortality in lowincome countries are 6 and 18 times higher, respectively, compared with wealthier countries. ${ }^{24-27}$ In addition, a third of global cervical cancer burden was associated with China and India, with 106,000 and 97,000 new cases diagnosed per year, respectively. ${ }^{20}$ In contrast, cervical cancer incidence and prevalence are remarkably lower in high-income nations, and the survival rate of cervical cancer patients is higher than in undeveloped and developing nations. In 2018, the American Cancer Society reported that around 13,240 women suffered from invasive cervical cancer, with approximately 4170 deaths. The oneyear and five-year survival rates of cervical cancer are approximately $87 \%$ in the United States of America. ${ }^{19,28}$ In contrast, survival rates in Uganda and Gambia's are less than $25 \% .^{19}$

Epigenetics and HPV strain type are two pathogenic risk factors responsible for the development of fatal cancers in the cervix. Approximately 70-75\% of cervical cancer cases are caused by high-risk HPVs, such as HPV-16 and HPV-18, while five additional oncogenic HPVs (HPV-31, HPV-33, HPV-45, HPV-52, and HPV-58) have been shown to elicit 15$30 \%$ of cervical cancer cases. ${ }^{29-32}$ 
Since the discovery of HPV oncoproteins and pathogenic factors regulate the generation and maintenance of HPVassociated malignancies, with the consistent induction of cervical cancer, which significantly encourages the development of HPV vaccines, including both prophylactic and therapeutic vaccines. ${ }^{33}$ However, the current success of HPV vaccines is available in the prophylactic vaccines. At present, the administration of prophylactic HPV vaccine, namely, GlaxoSmithKline's Cervarix ${ }^{\circledR}$, and Merck's Gardasil ${ }^{\circledR}$ and Gardasil ${ }^{\circledR} 9$ vaccines, is regarded as the primary prevention measure for HPV infections and cervical cancer. ${ }^{34,35}$ The bivalent HPV vaccine, Cervarix ${ }^{\circledR}$, $\operatorname{targets}$ HPV types -16 and -18 ; the quadrivalent HPV vaccine, Gardasil ${ }^{\circledR}$, targets HPV types $-6,-11,-16$ and -18 ; and the ninevalent HPV vaccine, Gardasil ${ }^{\circledR} 9$, targets HPV types $-6,-11,-16,-18,-31,-33,-45,-52$ and $-58 .{ }^{36}$ The three vaccines have been designed based on non-infectious virus-like particles (VLPs), which contain HPV capsid protein L1, produced in eukaryotic systems. ${ }^{9,37,38}$ Gardasil $^{\circledR}$ and Gardasil ${ }^{\circledR} 9$ contain an aluminum adjuvant, whereas Cervarix ${ }^{\circledR}$ contains monophosphoryl lipid A-based adjuvant (AS04). ${ }^{39,40}$ Through clinical trial testing, these vaccines have proven to be highly immunogenic, safe, efficient, and capable of stimulating antibody-based responses against HPV infection. ${ }^{40,41}$ They are able to protect up to $100 \%$ of females 9 to 26 years of age against HPV-associated cervical cancer. ${ }^{41,42}$

However, prophylactic HPV vaccines do not confer any cross-protection against further carcinogenic HPVs, and roughly $20 \%$ to $30 \%$ of malignancies associated with these viruses are unavoidable. ${ }^{39}$ Also, following vaccination with Cervarix ${ }^{\circledR}$, Gardasil $^{\circledR}$, or Gardasil ${ }^{\circledR}$ 9, a small number of users reported moderate side effects (eg, pain, inflammation, and erythema) at the injection site, diarrhea, and nausea. ${ }^{43}$ While the available prophylactic vaccines have proven effective at protecting the host against HPV infection, they do not eradicate tumor cells. Hence, it is essential to develop therapeutic peptide-based vaccines that can directly kill tumor cells and reduce the number of cancer-related deaths.

\section{Human Papillomaviruses (HPVs) and Infection HPV Genotypes and Risks}

HPV is a double-stranded, circular DNA virus within the family Papillomaviridae. The family includes five genera $(\alpha, \beta, \gamma, \mu$, and $v$ ), 48 species, and 206 genotypes. ${ }^{44-46}$ Initial experiments to detect the relationship between HPVs and cervical cancer date back to $1972 .{ }^{47}$ HPVs genotypes can be classified into high-risk and low-risk, according to their oncogenic potential: 15 HPV genotypes (HPV-16, -18, -31,-33,-35, -39, -45, -51,-52,-56,-58,-59,-68,-73, and -82) are considered highrisk HPV infection types that can cause invasive and fatal cervical cancer in females, and three other HPV genotypes (HPV-25, -53 , and -66) are considered to be possible high-risk types that might trigger cervical cancer. ${ }^{39,48-50} \mathrm{HPV}-16$ (55\%) and HPV$18(12.8 \%)$ are particularly carcinogenic, accounting for up to $70 \%$ of all cervical cell lesions. ${ }^{51,52}$ High-risk HPVs have been shown to directly modify the function of normal cell proteins, in addition to influencing gene expression. ${ }^{53}$ For example, through microarray analysis, high-risk HPV-31 was reported to up- and down-regulate 178 and 150 cellular genes, respectively, affecting normal cell growth, several keratinocyte-specific genes, and/or interferon (IFN)-responsive genes. ${ }^{53,54}$ In contrast, low-risk HPVs (HPV-6, -11, -40,-42, -43,-44, -54,-61, -70, -72, -81, and -89) rarely elicit malignant carcinomas. ${ }^{55}$ Skin lesions related to low-risk HPVs are typically self-limiting, non-life-threatening and can be eradicated by host immune responses. ${ }^{55}$ However, a small number of susceptible individuals with congenital immunodeficiency, whose innate immune system cannot detect the invasion of low-risk HPVs and effectively eliminate them, can develop recurrent respiratory papillomatosis and epidermodysplasia verruciformis (EV), resulting in an increased risk of suffering from cancers. ${ }^{55,56}$

\section{HPV Genome and Functions}

HPV is a non-enveloped small DNA virus (55 nm in diameter) containing approximately 8000 base pairs. ${ }^{46,56,57}$ The HPV genome contains eight to ten open reading frames, which can be divided into three regions: early gene coding region (E), late gene coding region (L), and long control region (LCR) of the non-coding region (Figure 1). ${ }^{46,58}$ Functionally, the early genes (E1-E2, E4-E7) are expressed at different stages of the HPV cycle and are responsible for viral replication and protein regulation; two of them (E6 and E7) are primary oncogenic factors. ${ }^{59}$ The late genes encode the two late capsid proteins, L1 and L2. ${ }^{59}$ Non-coding LCR is composed of the p97 core promoter and regulatory 

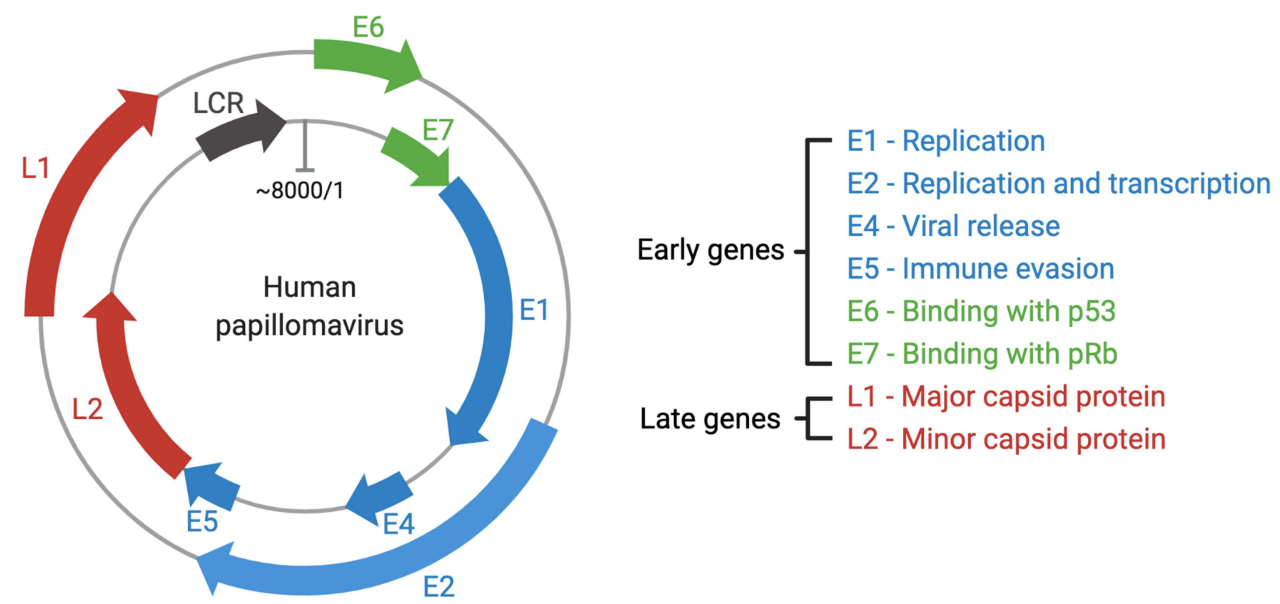

Figure I The HPV genome and gene functions. HPVs are typical non-enveloped double-stranded DNA viruses, with circular and approximately 8000 pairs in size. Most encode eight major genes, six genes located in the early regions and two in the late regions. The early genes can regulate the HPV genome replication and transcription, viral release, celling signaling and viral apoptosis, immune modulation, and structural modification of infected cells. ${ }^{60}$

sequence elements (enhancer and silencer sequences) responsible for regulating genetic information transmission in open reading frames. ${ }^{49,53}$

The particle structure of the HPV virus is an icosahedral capsid composed of 72 capsomers (Figure 2A). ${ }^{53}$ The late gene region encodes the viral capsid proteins, and each viral capsid is composed of five L1 and twelve L2 proteins. ${ }^{61}$ Capsid L1 protein contains five monomeric $55 \mathrm{kDa}$ units, while minor capsid L2 protein contains 12 copies of $74 \mathrm{kDa}$ units. ${ }^{62} \mathrm{~L} 1$, as the main capsid protein, can spontaneously associate with icosahedral capsid particles. As a secondary capsid protein, L2 can bind to a specific region of L1 and help the capsid assemble viral DNA to form a virion. However, L2 lacks the ability to form virus particles autonomously. ${ }^{63}$

Early gene coding regions are responsible for DNA replication, transcription, and the carcinogenic transformation of HPV viruses. ${ }^{61}$ Briefly, the E1 and E2 genes promote viral replication by interacting with specific regions in the HPV

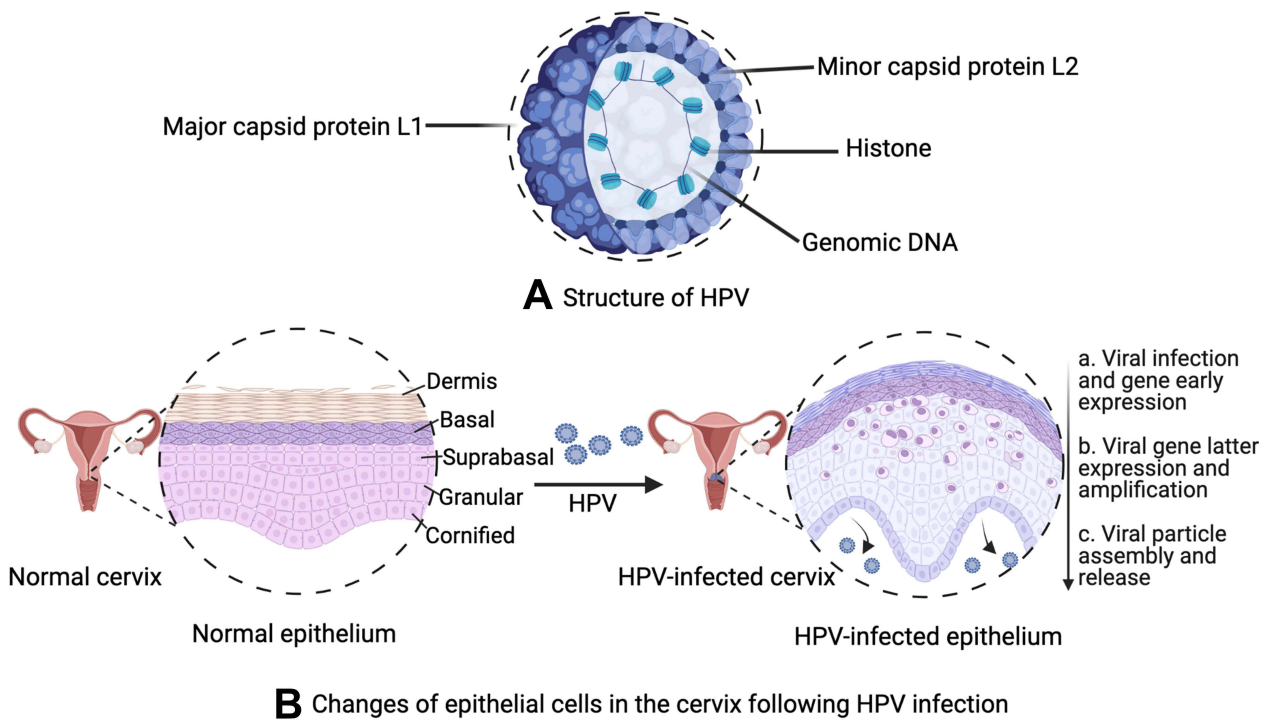

Figure 2 (A) Structure of HPV; (B) changes of epithelial cells in the cervix following HPV infection. (B): a. Viral infection and its early gene expression phase: HPV virus invade the basal layer of the stratified epithelium and initiates early gene (EI and E2) expression. The oncogenic virus quickly amplifies into $50-100$ copies per cell in EI- and E2-dependent manners, with a low copy number of HPV episomes maintained via replication with cellular DNA; b. Viral gene latter expression and amplification phase: one infected cell remains in the basal layer, while other cells continue to enter the suprabasal layer. The episomal DNA sequence of HPV diffuses into the nucleus of infected cells. There, it undergoes genetic replication and assembly; c. Viral particle assembly and release phase: the life cycle is directly controlled by differentiation of the host cell, where HPV viruses are released from keratinocytes. 
genome replication origin and co-opting cellular DNA replication components. ${ }^{64}$ E1 encodes virus-specific DNA helicase, which is highly conserved and directly activates the replication and amplification of HPV. ${ }^{46}$ Transcription, replication, and genome portioning of HPV are controlled by E2. ${ }^{49,64}$ The control of gene amplification, virus synthesis, release, and transmission has been associated with the E4 proteins. ${ }^{65}$ Furthermore, high-risk E4 proteins form amyloid fibers, which are used as biomarkers to diagnose HPV infection. ${ }^{65}$ The E5 gene product (about 80 amino acids) is present in all high-risk HPV types; it promotes tumor progression as an early oncoprotein. E5 is, therefore, considered to be a promising therapeutic target. ${ }^{66}$ It is expressed in the early stage of replication, forming small, hydrophobic, single membrane-spanning proteins that bind with platelet-derived growth factor receptors and epidermal growth factor receptors, leading to apoptosis and proliferation of normal cells and evasion of host immune responses. ${ }^{46,67}$ Research on the E5 protein has been challenging due to its small size, hydrophobicity, membrane localization, and low secretion level. ${ }^{66}$

Finally, E6 and E7 are important oncoproteins necessary for malignant conversion. They undergo continuous expression and retention throughout the life cycle of HPV-positive cancer cells. Inhibition of E6 and E7 protein expression causes senescence and apoptosis in indefinitely proliferating cancer cells. ${ }^{68} \mathrm{E} 6$ and E7 proteins are responsible for a variety of hallmark cancer pathways, namely, evasion of growth suppressors, blocking of the normal cellular life cycle, promotion of tumor cell proliferation and differentiation, and resistance to cancer cell death. ${ }^{3,59}$ Consequently, E6 and E7 are the main targets for therapeutic vaccine development. ${ }^{3}$

E6, as a major oncoprotein, is approximately 150-160 amino acids in length and around $18 \mathrm{kDa}$ in mass. ${ }^{3,69}$ E6 proteins contain four CXXC motifs, which can form two zinc fingers. Breaking any conserved regions can interfere with the activity of HPV E6 proteins. ${ }^{69}$ All zinc-finger domains are preceded by one hydrophilic amino-terminal region, divided by a hydrophobic domain, and subsequently linked with a short carboxy-terminal domain. ${ }^{69}$ High-risk HPV E6 proteins can degrade tumor suppressor p53 and PDZ proteins, which are the key regulatory factors in the E6 oncogenic pathway, augmenting the activation of telomerase and increasing tumor cell growth remarkably. ${ }^{69,70}$ Without the secretion of p53 in vivo, tumor cells proliferate uncontrolled and invasion persists. ${ }^{71}$ The E6 gene can also methylate the promoter of interferon-kappa (IFN-א) and inhibit IFN- $\kappa$ and other cytokines participating in the regulation of immune response, thereby promoting persistent infection by the HPV virus. ${ }^{72}$

E7 is a small phosphoprotein of about 100 amino acids. It contains three conserved regions (CR1, CR2, and CR3) ${ }^{3,73}$ A small part of the sequence from CR1 and the entire CR2 region are similar to adenovirus E1A proteins and the large $\mathrm{T}$ antigen of simian virus 40 (SV40). ${ }^{3}$ Conserved sequences ("LXCXE" motifs) are located in CR2 and bind to retinoblastoma tumor suppressor protein $(\mathrm{pRb})$. CR3 is located at the C-terminal region of $\mathrm{E} 7$ and consists of two CXXC zinc-binding motifs separated by $29-30$ amino acid residues. ${ }^{74}$ The conserved region is sufficient to control zinc-dependent dimerization, and it regulates the cell cycle and apoptosis. ${ }^{75-77}$ The CR2 region is implicated in complex formation with $\mathrm{pRb}$ due to the existence of the paramount $\mathrm{pRb}$-binding core sequence LXCEX and an enzymic site for casein kinase II (CKII) ${ }^{74}$ By encoding oncoproteins, E7 causes controlled cell proliferation by binding and inactivating regulatory repressor $\mathrm{pRb}$, which is the most significant target in the E7 regulatory pathway. ${ }^{68}$ Specifically, the transcription factor E2F is an essential regulator of cell cycle entry into the S-phase, and is also a downstream target of $\mathrm{pRb} .{ }^{46,78}$ When cells are infected by HPV, the E7 gene product binds to $\mathrm{pRb}$, producing the E7-pRb complex. This interferes with the normal function of $\mathrm{pRb}$, which triggers the activation of E2F and prematurely initiates the S-phase of the cell life cycle, affecting HPV DNA synthesis and replication and the proliferation of cervical cancer cells. ${ }^{68,79}$

\section{Pathogenesis of HPV}

HPVs infect epidermal or mucosal epithelial cells. Most infections are cleared by the host's immune system. However, persistent HPV infections not cleared by the immune system led to benign cervical lesions. Cervical intraepithelial neoplasia (CIN) is commonly classified into three stages: CIN1, CIN2, and CIN3. CIN1 is the low-grade lesion stage characteristic of a variety of HPV infections. More than $80 \%$ of CIN1 cases are cleared by the immune system within several months. ${ }^{52,56}$ However, HPV infection not cleared by innate immune responses can develop into CIN2/3 as highgrade CIN lesions, eventually causing invasive cervical cancer (Figure $2 \mathrm{~B}$ ). ${ }^{52,58}$ 
Micro-wound is the primary pathway for HPVs to infect multi-layered stratified epithelium in the ectocervix, whereby the virus can enter the basal lamina. ${ }^{48,80,81}$ Infected basal cells form a reservoir for cervical cancer infections. ${ }^{81}$ In the early stage of the HPV life cycle, the early promoter can be activated in the infected basal layer cell to initiate expression of the E1 viral helicase that interacts with E2. The viral episomes are then rapidly replicated and amplified. ${ }^{48,81}$ At this stage, the viral genome maintains a low level of intact genome replication. ${ }^{81,82}$ As infected basal cells begin to divide, their daughter cells progressively migrate to the upper layers, accompanied by epithelial differentiation. Subsequently, cell division accelerates bulk amplification of the viral genome, triggering late gene expression and completing virosome assembly and release. ${ }^{81,83}$

\section{Immune Response to HPV Infection}

The human immune system has two fundamental responses: innate and adaptive (Figure 3), which protect the body from pathogens, as well as toxic and allergenic substances. The innate immune system is the first line of defense and provides a general protective response against microbial invaders and foreign proteins. It is non-specific, short-term, and noninducible. This system includes physical barriers (skin or epithelial cell layer), mucosal layers, the gastrointestinal and genitourinary tracts, and epithelial cilia that prevent pathogens from entering the host. ${ }^{84}$ In addition, it uses chemicals and non-specific immune cells, such as natural killer cells, phagocytes, dendritic cells (DCs), and mast cells from bone marrow progenitors, to attack and kill invading pathogens. ${ }^{84}$

Sustained invasion by pathogens can trigger adaptive immune responses (Figure 3). The distinctive feature of the adaptive immune response is the establishment of a specific, long-term immune memory. Generally, an adaptive immune response needs around 7-14 days to establish. The adaptive immune response expresses a strong host defense for secondary infections due to the prolonged immune response. When the host is restimulated, memory cells trigger a faster and more effective immune response. The adaptive immune response also involves the secretion of specific cytokines (eg, interleukin (IL)-4, IL-10, tumor necrosis factor (TNF)- $\beta$, interferon (IFN)- $\gamma$ ) that bind to specific

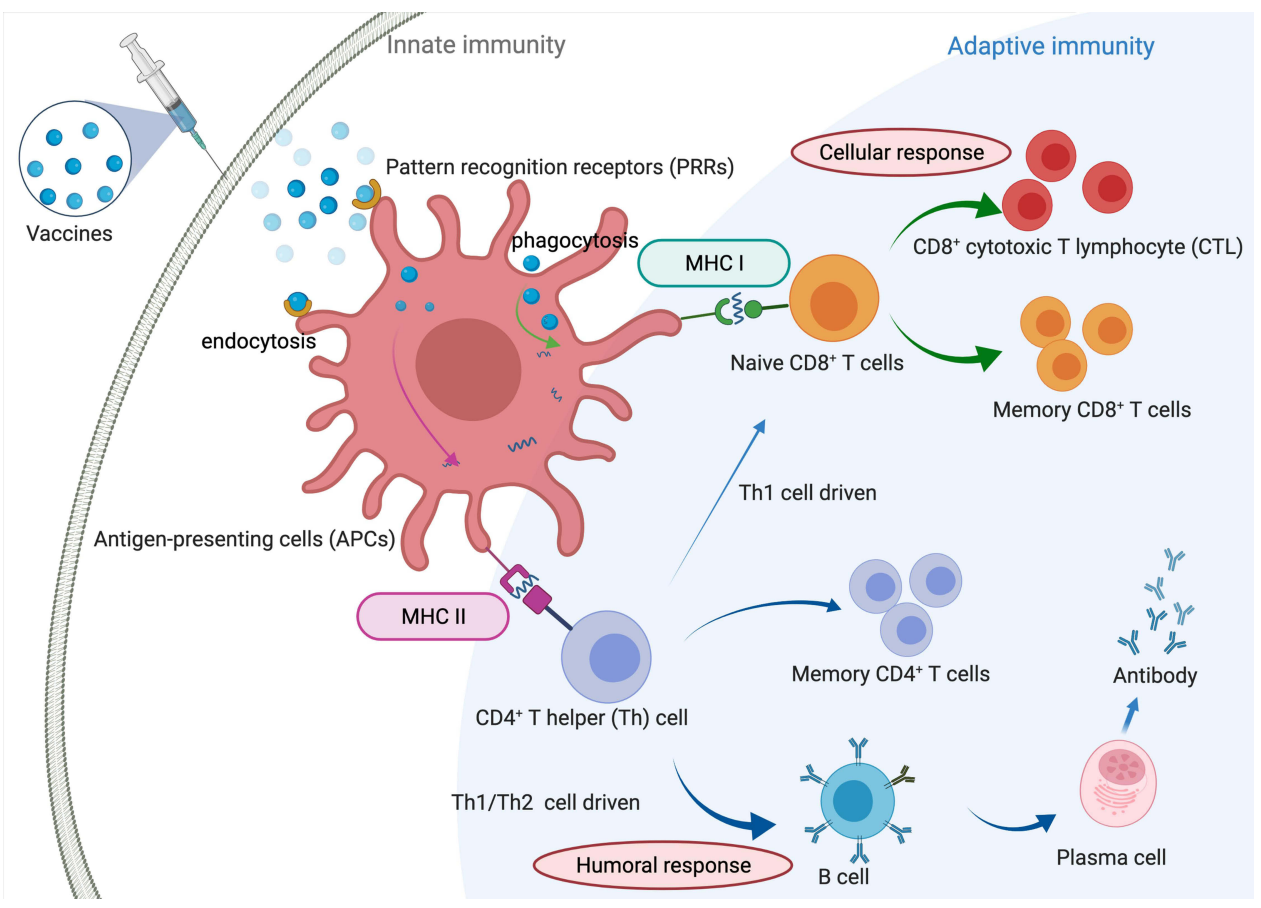

Figure 3 Human immune responses against invasive pathogens. The human immune system has been classified into two general groups, including innate and adaptive immune responses. Innate immune cells stimulate rapid reactions, whereas adaptive immune cells have a delayed response, producing immunological memory. ${ }^{86}$ Rapid responding innate cells include polymorphonuclear cells, mast cells, macrophages, and dendritic cells, which are capable of internalizing and destroying invading microbes as well as the secretion of cytokines and proinflammatory chemokines, inducing other immune cells to the site of infection. Macrophages and DCs, as antigen-presenting cells (APCs), is capacity to ingest pathogens and produce pathogen peptides on their cell surface, which can be recognized by major histocompatibility complex (MHC) class I and MHC-II, with the induction of cellular immune response and humoral immune response, respectively. 
receptors on the surface of immune cells, triggering cellular signaling cascades that regulate immune defenses against antigens. $^{84,85}$

The innate immune response recognizes pathogen-associated molecular patterns (PAMPs) through pattern recognition receptors (PRRs) on the surface of antigen-presenting cells (APCs). APCs take up endocytosed or phagocytized cells and cleave invading pathogens (or antigens) into small peptides. These are then presented by major histocompatibility complex (MHC)-I or MHC-II, which can be recognized by CD8 cells or CD4 cells, respectively, resulting in the stimulation of cellular and/or humoral immunity against invasive pathogens.

The MHC-I stimulation pathway activates cytotoxic T lymphocytes (CTLs, $\mathrm{CD}^{+} \mathrm{T}$ cells), which secrete cytokines to target and kill infected cells or tumor cells: this is the foremost immune pathway to eliminate tumor cells. ${ }^{87} \mathrm{CTLs}$ primarily recognize pathogenic antigens derived from intracellular proteins, while humoral immunity is associated with extracellular antigens and antibody-based immune responses. ${ }^{87}$ However, cellular immunity against tumor invasion is stimulated by tumor antigens, which are specific antigen substances secreted in tumor cells. Typical tumor antigens are comprised of tumor-specific antigens (TSA) that only exist on tumor cells, ${ }^{88-90}$ and tumor-associated antigens (TAA), ${ }^{91-93}$ which can be expressed in high levels in cancer cells but may also be found in lower levels in healthy cells.

Both cytotoxic and humoral immune responses require activation of $\mathrm{T}$ helper cells $\left(\mathrm{Th}, \mathrm{CD} 4^{+} \mathrm{T}\right.$ cells). ${ }^{87} \mathrm{CD} 4^{+}$ $\mathrm{T}$ helper 1 (Th1) cells can secrete different proinflammatory cytokines, including interleukin (IL)-2, IL-10, tumor necrosis factor (TNF)- $\alpha$, and interferons, which are the hallmarks of mediated immune responses. Secreted proinflammatory cytokines can activate cytotoxicity against tumor pathogens, enhance anti-tumoral abilities of macrophages and natural killer cells, and increase tumor antigen presentation. $\mathrm{CD}^{+} \mathrm{T}$ helper 2 (Th2) cells can produce several antiinflammatory cytokines, such as IL-4, IL-5, IL-6, IL-10, and IL-13, and promote B cells to antibodies against helminths, infections, and allergic disorders. ${ }^{94}$

Under normal conditions, Th1 and Th2 immunity are balanced; ${ }^{95}$ the existence of tumor cells can interfere with this balance. Following the downregulation of adaptive immunity, Th2 immunity is enhanced and Th1 immunity decreases, allowing tumor progression. A shift towards Th1 immunity, in contrast, can lead to tumor regression. ${ }^{95}$

Cancer immune therapeutics and vaccines are designed to trigger cellular immune responses targeting intracellular antigens. Specifically, vaccine candidates need to be presented as endogenous antigens that are processed in the proteasome of the host cytoplasm and presented by $\mathrm{MHC}$ I to $\mathrm{CD}^{+} \mathrm{T}$ cells, generating a cell-mediated immune response. Cell-mediated immunity established by this pathway is essential for the elimination of HPV-infected cells.

\section{Anticancer Vaccines}

As the pivotal public health tool, the main principle of vaccination is the stimulation of adaptive immunity and immune memory to provide long-term protection against infections or diseases, reducing or eliminating the risk of invasive diseases or disease-related complications, without triggering any considerable side effects. ${ }^{6}$ As the second line of immune defense, the adaptive immune system recognizes antigens with high concentricity and specificity. ${ }^{6}$ Prophylactic vaccination aims to activate adaptive immunity and induce neutralizing antibodies prior to natural infection. On the other hand, therapeutic vaccines, which utilize the cellular arm of the immune system, seek to specifically target existing disease/infection. ${ }^{96}$ However, triggering adaptive immunity against tumor cells is difficult, as these cells are similar to normal human cells and, therefore, are often tolerated by the immune system. Fortunately, in the case of cervical cancer, non-human proteins (derived from the virus) can be targeted by tumor-specific cell immune responses, as they are independent of central tolerance mechanisms. ${ }^{97}$

Over the past decades, various types of vaccines have been designed to enhance CTL-based immune responses against cervical cancer, including vaccines based on peptides, proteins, nucleic acids (DNA and RNA), whole cells, and vectors (bacterial and viral) (Table 1). ${ }^{10,33}$ Among them, peptide-based vaccines generate the most controlled immune responses as they only use minimal antigen components. They are developed through meticulous antigen selection and the use of purpose-designed adjuvants, which have allowed remarkable breakthroughs in preclinical and clinical development of therapeutic cervical cancer vaccines. $6,13,98$ 
Table I Features of the Most Common Therapeutic Vaccine Candidates Against Cervical Cancers 6,99,100

\begin{tabular}{|c|c|c|c|c|c|}
\hline $\begin{array}{l}\text { Vaccine } \\
\text { Type }\end{array}$ & Vaccine Composition & $\begin{array}{l}\text { Immuno- } \\
\text { Genicity }\end{array}$ & Toxicity & Advantages & Disadvantages \\
\hline $\begin{array}{l}\text { Viral/ } \\
\text { bacterial } \\
\text { vector }\end{array}$ & $\begin{array}{l}\text { Tumor and/or viral antigens induced } \\
\text { by oncogenesis are delivered by live } \\
\text { attenuated bacterial/viral vectors }\end{array}$ & High & High & $\begin{array}{l}\text { - Highly immunogenic } \\
\text { signal with broad immunity } \\
\text { - Wide range of vector } \\
\text { selection } \\
\text { - Easy large-scale } \\
\text { production } \\
\text { - Can be engineered }\end{array}$ & $\begin{array}{l}\text { - Several undesired side-effects, } \\
\text { such as pre-existing antiviral } \\
\text { immunity and inheritable } \\
\text { immune defects } \\
\text { - Limited efficacy: reuse the } \\
\text { same vector } \\
\text { - Redundant responses to } \\
\text { vectors }\end{array}$ \\
\hline $\begin{array}{l}\text { Antigen- } \\
\text { primed } \\
\text { dendritic } \\
\text { cells (DCs) }\end{array}$ & $\begin{array}{l}\text { Personalized isolation and } \\
\text { cultivation of DCs in cancer patients }\end{array}$ & High & Low & $\begin{array}{l}\text { - Role as natural adjuvants } \\
\text { - Easily control antigen } \\
\text { presentation and antigen } \\
\text { presenting cell (APC) } \\
\text { stimulation }\end{array}$ & $\begin{array}{l}\text { - Very expensive } \\
\text { - Requires a leukapheresis } \\
\text { facility } \\
\text { - Difficult to consistently } \\
\text { produce with large yields }\end{array}$ \\
\hline $\begin{array}{l}\text { Whole } \\
\text { tumor cells }\end{array}$ & $\begin{array}{l}\text { Isolated and manipulated tumor } \\
\text { cells ex vivo }\end{array}$ & Moderate & High & $\begin{array}{l}\text { - Significantly broad and } \\
\text { does not require clear } \\
\text { definition of antigens } \\
\text { - Allogeneic cells produced } \\
\text { on a large scale }\end{array}$ & $\begin{array}{l}\text { - Unstable efficacy and purity of } \\
\text { vaccines } \\
\text { - Time-consuming and } \\
\text { expensive to produce } \\
\text { - Risk of implanting new cancers } \\
\text { - Risk of autoimmune responses }\end{array}$ \\
\hline $\begin{array}{l}\text { Nucleic } \\
\text { acid-based }\end{array}$ & $\begin{array}{l}\text { Injection DNA plasmid/RNA } \\
\text { replicon: encodes target antigens }\end{array}$ & Moderate & Moderate & $\begin{array}{l}\text { - Mimics natural antigen } \\
\text { presentation, good efficacy } \\
\text { - Can be engineered and } \\
\text { express multiple genes }\end{array}$ & $\begin{array}{l}\text { - Poor stability, cold chain } \\
\text { required } \\
\text { - Requires an effective (but } \\
\text { often toxic) delivery system }\end{array}$ \\
\hline $\begin{array}{l}\text { Peptide- } \\
\text { based }\end{array}$ & $\begin{array}{l}\text { Antigenic peptides: about } 6-20 \\
\text { amino acids, with adjuvant and/or } \\
\text { delivery system }\end{array}$ & Moderate & Low & $\begin{array}{l}\text { - Safe, stable, easy to } \\
\text { manufacture } \\
\text { - Multiple adjuvants and } \\
\text { delivery systems can be } \\
\text { used }\end{array}$ & $\begin{array}{l}\text { - Low immunogenicity, requires } \\
\text { a strong adjuvant } \\
\text { - Problematic delivery } \\
\text { - Limitation in MHC-specificity }\end{array}$ \\
\hline $\begin{array}{l}\text { Protein- } \\
\text { based }\end{array}$ & Fusion proteins, with adjuvant & Moderate & Low & $\begin{array}{l}\text { - Multiple epitopes in one } \\
\text { pathogenic protein } \\
\text { - Easy large-scale } \\
\text { production } \\
\text { - No limitation in MHC- } \\
\text { specificity }\end{array}$ & $\begin{array}{l}\text { - Low immunogenicity, requires } \\
\text { strong adjuvant } \\
\text { - More expensive than peptide- } \\
\text { based subunit vaccine } \\
\text { - Risk of triggering undesired } \\
\text { immune responses }\end{array}$ \\
\hline
\end{tabular}

\section{Development of Peptide-Based Therapeutic HPV Vaccine}

Peptide-based vaccines utilize the minimal components (epitopes) from pathogenic or oncoproteins to induce a specific immune response against infections and cancers. ${ }^{15,16,98,101}$ Peptide vaccines can be commonly produced at a large scale and in stable and water-soluble form. ${ }^{15}$ Compared to new types of vaccines (including live vector-based vaccines, DNA vaccines, and RNA vaccines), peptide-based vaccines are easily and exclusively produced by chemical synthetic approaches, directly avoiding all biological contaminations of the antigens without the induction of allergic and autoimmune responses. ${ }^{102,103}$ Furthermore, synthesized peptides can be fully and precisely characterized as a chemical entity, with the utilization of classical analysis methods (including mass spectrometry and high-performance liquid chromatography). Peptide sequences can be simply produced and easily reproduced as well as fast and cost-effective due to the use of solid-phase peptide systems with automatic synthesizers and the application of microwave techniques, with 
Table 2 Epitope Sequences of Peptide-Based Therapeutic HPV Vaccines

\begin{tabular}{|c|c|c|c|}
\hline Gene of HPV & Epitope and Sequence & $\begin{array}{l}\text { Activation in Immune } \\
\text { Response }\end{array}$ & Ref \\
\hline \multirow[t]{8}{*}{ HPV-I6 E7 } & $\mathrm{E7}_{48-54}(\mathrm{DRAHYNI})$ & \multirow[t]{2}{*}{$\mathrm{CD}^{+} \mathrm{T}$ cell } & 115 \\
\hline & $\mathrm{E7}_{50-62}(\mathrm{AHYNIVTFCCKCD})$ & & 115 \\
\hline & $\mathrm{E7}_{49-57}$ (RAHYNIVTF) & \multirow[t]{6}{*}{$\mathrm{CD}^{+} \mathrm{T}$ cell } & 115 \\
\hline & $\mathrm{E7}_{7-15}$ (TLHEYMLDL) & & 118 \\
\hline & E7/1-20 (YMLDLQPETT) & & 118 \\
\hline & E7 $82-90$ (LLMGTLGIV) & & 118 \\
\hline & $\mathrm{E}_{86-93}(\mathrm{TLGIVCPI})$ & & 119 \\
\hline & $\mathrm{E7}_{67-75}$ (LCVQSTHVD) & & 119 \\
\hline \multirow[t]{5}{*}{ HPV-16 E6 } & E6 $29-38$ (TIHDIILECV) & \multirow[t]{5}{*}{$\mathrm{CD}^{+} \mathrm{T}$ cell } & 121 \\
\hline & E6 $_{43-57}$ (QLLREVYDFAFRDL) & & 122 \\
\hline & $\mathrm{E}_{50-57}$ (YDFAFRDL) & & 124 \\
\hline & $\mathrm{E6}_{49-57}$ (VYDFAFRDL) & & 120 \\
\hline & $\mathrm{E}_{127-135}(\mathrm{DKKQRFHNI})$ & & 119 \\
\hline \multirow[t]{4}{*}{ HPV-I6 E5 } & $\mathrm{E}_{25-33}$ (VCLLIRPLL) & \multirow[t]{2}{*}{$\mathrm{CD}^{+} \mathrm{T}$ cell } & 126 \\
\hline & $\mathrm{E5}_{63-7 I}(\mathrm{YIIFVYIPL)}$ & & 127 \\
\hline & E5 $_{64-78}$ (IPLFLIHTHARFLIT) & \multirow{2}{*}{$\begin{array}{c}\text { Both } \mathrm{CD}^{+} \mathrm{T} \text { cell and } \mathrm{CD}^{+} \\
\mathrm{T} \text { cell }\end{array}$} & 127 \\
\hline & $\mathrm{E5}_{50-63}$ (SAFRCFIVYIIFVY) & & 126 \\
\hline
\end{tabular}

higher purity and yield, in comparison to new types of vaccines. ${ }^{15}$ Peptides can be designed to bind specific objectives based on the selection of one or multiple epitopes against invasive pathogens. ${ }^{15}$

Unfortunately, peptide vaccine antigens bearing B cell and/or $\mathrm{CD} 8^{+}$epitopes often lack $\mathrm{Th}$ epitopes, which significantly reduces vaccine efficacy. ${ }^{17}$ Furthermore, peptides can be easily cleaved by peptidases. ${ }^{29,78,80}$ Finally, peptides are not promptly recognized by APCs, so do not have the ability to stimulate significant immune response on their own. As a result, peptides must be administered with strong adjuvant, an appropriate delivery system and multiple dosing is usually required. ${ }^{17,99}$ One of the most promising strategies to overcome these shortcomings is the use of nanoparticle-based delivery systems/adjuvants. ${ }^{17,101}$ Therefore, the selection of antigenic epitopes, immunostimulatory adjuvants, and delivery systems (or vaccine formulation) are all crucial elements in the development of effective anticancer vaccine (Figure 4). ${ }^{15}$

\section{Selection of Antigenic Epitopes}

The first prerequisite for the development of peptide-based vaccines is the determination of antigenic proteins from which appropriate epitopes can be selected. ${ }^{11}$ To achieve broad coverage of a wide range of pathogen subtypes, peptidebased vaccine must contain highly conserved epitopes or a combination of diverse, variable epitopes. ${ }^{15}$ Generally, antigen epitopes can be classified as $\mathrm{B}$ or $\mathrm{T}$ cell $\left(\mathrm{CD}^{+}\right.$or $\left.\mathrm{CD} 8^{+}\right)$epitopes that can trigger humoral and cellular immune responses. HPV therapeutic peptide-based vaccines have to trigger cellular immunity and, therefore, $\mathrm{CD} 8^{+}$and $\mathrm{CD} 4^{+}$ epitopes need to be incorporated in vaccine formulations.

The most important factor in antigen selection is how epitopes bind to the MHC molecule. ${ }^{104}$ MHC I and MHC II molecules have similar 3D-structures with bound peptides located in a groove formed by two $\alpha$-helices. The type of bond 


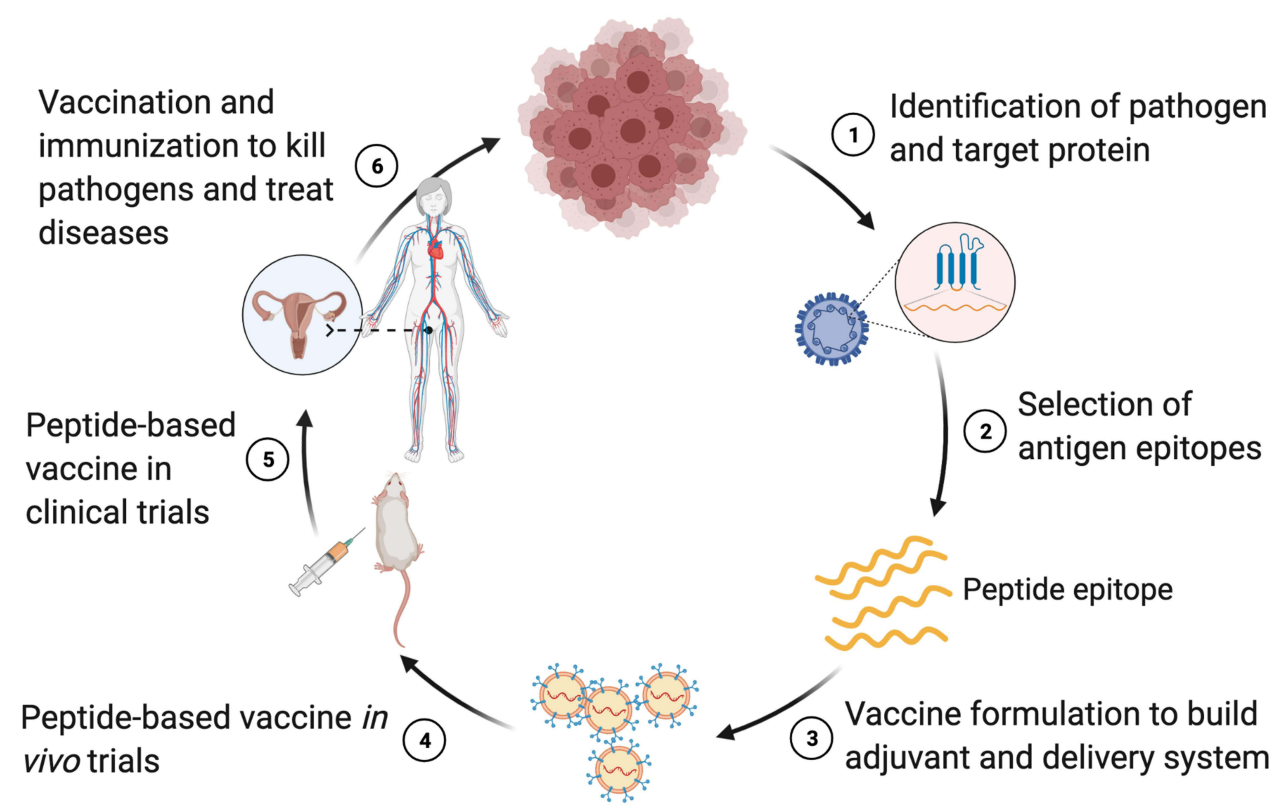

Figure 4 Schematic process of the development of peptide-based vaccines. The whole and successful process of developing peptide-based vaccines is classified into six main steps, including the identification of pathogens and target proteins, selection of antigen epitopes, vaccine formulation to build vaccine candidates, in vivo trials of peptidebased vaccine candidates, clinical trials of vaccine candidates, and final vaccination and immunization in humans against infectious diseases.

between peptide residues and the MHC molecule is affected by the charge distribution, shape, and hydrophobicity of the binding groove. The binding site for MHC class I molecules is a groove that can only hold about 8-11 amino acids with its C-terminal end binding to the F-pocket due to closure of the binding groove at both ends by conserved tyrosine residues. ${ }^{15,104,105}$ In contrast, the binding grooves of MHC class II molecules are open and can bind peptide ligands of 11-20 amino acids in length as the N-terminal ends can extend from the P1 pocket. ${ }^{104}$ The number of distinct short peptides that exist creates a massive $\mathrm{T}$ cell epitope space to be explored. ${ }^{105} \mathrm{In}$ each MHC class molecule, the promotion of peptide exchange for certain peptides can be achieved via specific "catalysts", including tapasin for MHC class I and HLA-DM for MHC classes II. These catalysts are similar to enzymes that can reduce the energy barrier for peptide exchange without breaking formed covalent bonds during the exchange reaction. ${ }^{106}$ Additionally, human leukocyte antigen (HLA) genes encode peptide-presenting MHC molecules, which are polygenic and strongly polyallelic. Different HLA alleles encode MHC mutants with different peptide binding and T-cell receptor binding priorities. ${ }^{105}$ Thus, selection of CTL epitopes must consider both immunogenicity and compatibility with a wide range of HLA alleles.

The current reliance on computational methods to predict epitopes has opened up a new mindset in vaccine design, introducing the concept of reverse vaccinology, which involves the process of vaccine development through immunoinformatics to evaluate multiple proteomes, identify and select target epitopes, and overlap epitope combinations. ${ }^{107} \mathrm{~A}$ variety of antigen prediction tools exist, which can be broadly classified as position specific scoring matrix (PSSM)-based, artificial intelligence (AI)-based, structure-based methods, and meta-analysis studies (mixture of other methods). ${ }^{108,109}$ Among them, MAPP, NetCTL, NetCTLpan, MHCpathway and PickPocket are the most popular data-driven methods. ${ }^{104,110}$ A systematic and detailed review of MHC I/II epitope design tools for peptide-based HPV vaccines has been previously presented by Kaliamurthi et al. ${ }^{107}$ The group also reported the identification of HPV-45 and HPV-58 genotypic epitopes based on computational immunology and structural vaccinology approaches. ${ }^{11,112}$

\section{Application of Antigenic Epitopes in Therapeutic HPV Peptide-Based Vaccines}

E6 and E7 proteins are the two major oncogenes of HPV-associated cancers. These proteins regulate the life cycle of host cells through multiple pathways, and they are excellent targets for cervical cancer therapeutic peptide-based vaccines. ${ }^{100,113}$ However, this implies that immunization against specific epitopes of E6 and E7 can precisely induce and target CTL 
responses (Table 2) ${ }^{113}$ Most therapeutic peptide-based vaccine candidates against HPV have used E7 epitopes as the antigen because of its high affinity to retinoblastoma protein $(\mathrm{pRb})$, effective control of the early HPV life cycle, elimination of tumor immortalization, and its capacity to produce a more effective cellular immune response compared to E6. ${ }^{96}$

HPV-16 E7 protein epitope, E7 $43-77$ (GQAEPDRAHYNIVTFCCKCDSTLRLCVQSTHVDIR) comprises one CD8 ${ }^{+}$ $\mathrm{T}$ cell epitope (E7 $49-57, \mathrm{RAHYNIVTF})$ and two $\mathrm{CD}^{+} \mathrm{T}$ cell epitopes (E7 $48-54, \mathrm{DRAHYNI} \mathrm{E}_{50-62}$, AHYNIVTFCCKCD). ${ }^{114}$ Its shorter version, 8Q epitope (E744-62, QAEPDRAHYNIVTFCCKCD), was also widely studied. ${ }^{115}$ Tindle's team demonstrated that $\mathrm{E} 7_{48-54}$-activated cells from mouse lymph nodes produced cytotoxin against tumor cells. ${ }^{116}$ Furthermore, E7 $44-62$ epitope was able to induce antibody production (as it is carrying B-cell epitope, as well). ${ }^{116}$ HPV-16 E7 7-15 (TLHEYMLDL), E7 $11-20$ (YMLDLQPETT), E7 $82-90$ (LLMGTLGIV), E86-93 (TLGIVCPI), E7 $77-75$ (LCVQSTHVD) were also confirmed to be $\mathrm{CD} 8^{+} \mathrm{T}$ cell epitopes, differentially restricted to HLA alleles. ${ }^{117,118}$

Modification of epitope structure may significantly alter immune responses. When 8Q C-terminus pentapeptide fragment (QAEPDRAHYNIVTFCCKCD) was altered to avoid disulphide bond formation, producing shortened $8 \mathrm{Q}_{\min }$ (E744-57, QAEPDRAHYNIVTF), 8Q Ser $_{\text {(QAEPDRAHYNIVTFSSKSD), and 8Q }}$ Lys (QAEPDRAHYNIVTFSKKK), only $8 \mathrm{Q}_{\min }$ maintained the ability to stimulate strong CTL responses. ${ }^{115} 8 \mathrm{Q}_{\mathrm{Ser}}$ and $8 \mathrm{Q}_{\mathrm{Lys}}$ were likely not processed appropriately in DCs and, thus, did not activate the MHC I pathway. ${ }^{115}$

HPV-16 E6 ${ }_{49-57}$ (VYDFAFRDL) was found to be a typical CTL immunodominant epitope, with restriction to the HLAA24 allele. ${ }^{119,120}$ E6 $_{87-95}$ (CYGYTTL) and E6 ${ }_{98-106}$ (QYNKPLCDL) were similarly HLA-A24-restricted CTL epitopes, but their affinities to HLA molecules were not consistent. ${ }^{120}$ As a CTL epitope, E6 $29-38$ (TIHDIILECV) was only effective in limited cervical carcinoma cell lines due to a low release of inflammatory cytotoxin by HPV 16 E6 $29-38^{-s p e c i f i c}$ T cells. ${ }^{120}$ Multiepitope peptide-based vaccine, including a combination of HPV-16 E6 $43-57$ (QLLREVYDFAFRDL), E7 $8_{\text {min }}{ }^{121} \mathrm{E}_{43-57}$, E7 8Q, ${ }^{122} \mathrm{E}_{50-57}$ (YDFAFRDL), and E7 $49-57$ epitopes, is one possible solution to overcome this issue. ${ }^{123}$ An HPV-16 multiepitope vaccine candidate was designed to present multiple CTL epitopes of $\mathrm{H} 2-\mathrm{D}^{\mathrm{b}}$ and $\mathrm{H} 2-\mathrm{K}^{\mathrm{b}}$ restricted, E6 49-57, E6 127-135 (DKKQRFHNI), E749-57, and E7 67-75. It activated specific T cells and inhibited tumor growth. ${ }^{118}$ Moreover, vaccine candidates constructed of long, overlapping peptides are selected peptide sequences from E7/E6 oncogenic proteins overlapping with their neighbored peptides. As an HPV vaccine, the multiepitope candidate had a high binding affinity to MHC molecules, was directly taken up by APCs, facilitated the MHC I stimulation pathway to activate cellular immunity, secreted cytotoxin, and offered a wide range of allele coverage. ${ }^{87,124}$

E5 protein can also be a potential target for therapeutic vaccine development, as it is expressed in the early stages of HPV infection and is responsible for both pro-apoptotic factors and tumor survival pathway modulation, the oncogenic cell cycle, and tumor proliferation. ${ }^{125}$ Based on immunoinformatics analysis, Kumar et al identified the most potent MHC $\mathrm{I}$ and MHC II antigenic determinants in E5 to be E5 50-63 (SAFRCFIVYIIFVY) and E5 $5_{64-78}$ (IPLFLIHTHARFLIT), respectively. ${ }^{125}$ In addition, reverse immunology confirmed that E5 $5_{25-33}$ (VCLLIRPLL) and E5 63-71 (YIIFVYIPL) had the ability to induce cell-mediated immune responses and affected tumor growth in the $\mathrm{C} 3$ cell line of a preclinical mouse model. $^{126}$

As mentioned above, $\mathrm{CD}^{+}$epitopes were identified in HPV proteins; however, universal $\mathrm{T}$ helper epitopes, unrelated to HPV, can also be applied in vaccine design. This is because, in contrast to $\mathrm{CD} 8^{+}$and $\mathrm{B}$ cell epitopes, $\mathrm{CD}^{+}$epitopes do not need to be pathogen-specific. Universal $\mathrm{T}$ helper epitopes are the MHC-II antigenic determinants that cover a broad range of HLA alleles in the global population and stimulate universal immune responses. ${ }^{15,127}$ For example, Pan DR epitope peptide (PADRE; AKFVAAWTLKAAA) stimulates human peripheral blood mononuclear cells to produce more vital immune stimulation than natural Th epitopes. ${ }^{128}$ This artificial epitope demonstrated its efficacy and safety in clinical trials. ${ }^{129-131}$ When incorporated in HPV vaccine, PADRE induced specific proliferation responses and was well tolerated in patients with advanced cervical carcinoma. ${ }^{130,131}$ The addition of influenza virus haemagglutinin-derived $\mathrm{CD}^{+}$peptide $\left(\mathrm{HA}_{307-319}\right.$, PKYVKQNTLKLAT-C) and tetanus toxin-derived $\mathrm{CD}^{+}$peptide ( $\mathrm{TT}_{830-844}$, CG-QYIKANSKFIGITEL) also increased HPV-associated specific antitumor activity in pre-clinical studies. $^{132}$ 


\section{Adjuvants and Delivery Systems in Peptide-Based HPV Therapeutic Vaccines}

To stimulate immune responses against a peptide and avoid immune tolerance in the tumor microenvironment, a suitable adjuvant is essential. Adjuvants serve mainly as Toll-like receptor (TLR) agonists. ${ }^{15,133}$ TLRs commonly recognize a variety of PAMPs, activating signaling pathways leading to the production of inflammatory cytokines and inducing innate, or even adaptive immune responses. ${ }^{134}$

In addition to aluminum salts (alum), the only widely approved adjuvant for use in human vaccines, other adjuvants, such as MF59, AS01, CpG-ODN, AF03, AS03, and AS04, have gradually been endorsed for human use in certain vaccines and countries over the past 20 years. ${ }^{135}$ Aluminum-based adjuvants are poor stimulators of cellular immune responses, so they are frequently used in prophylactic HPV vaccines rather than therapeutic vaccines; for example, HPV16/18 AS04 (monophosphoryl lipid A with aluminum hydroxide)-adjuvanted vaccine (Cervarix ${ }^{\circledR}$-GSK) had high, sustained IgG levels in clinical trials and was authorized in 2007. ${ }^{136,137}$ Squalene-based emulsion adjuvants, such as MF59, AF03, and AS03, have been commonly used for vaccine candidates to promote strong humoral and cellular immune responses against invasive pathogens. ${ }^{135}$ Other emulsion-based adjuvants, complete Freund's adjuvant (CFA) and incomplete Freund's adjuvant (IFA)-based Montanide ISA 51 and 720, were examined in HPV therapeutic vaccine formulations. ${ }^{96,116,138}$ In addition, synthetic oligodeoxynucleotides (ODNs) containing CpG motifs form the important CpG-ODN adjuvants, which stimulate APCs and activate humoral and cellular immune responses. CpG-ODN has been broadly used in therapeutic cancer vaccines in both preclinical and clinical trials due to its high affinity with TLR-9, prolongation of $\mathrm{CD}^{+} \mathrm{T}$ cells in cellular immunity, and good safety profile. ${ }^{139}$

A variety of experimental adjuvants and self-adjuvanting nanoparticle-based delivery systems have also been tested to stimulate stronger CTL responses against cervical cancer, especially for peptide-based antigens (Table 3). These include nanoparticle-based systems, such as polymeric nanostructures, liposomes, and virus-like particles. ${ }^{140}$ Nanoparticles can mimic pathogens, are more readily taken up by APCs, are more likely to reach the lymphatic system, can accumulate in lymph nodes, and, most importantly, can induce CTL responses by loading internalized antigen on MHC I molecules via antigen cross-presentation. ${ }^{15,141}$

\section{Emulsion-Based Adjuvants}

Two types of emulsions: water-in-oil and oil-in-water, are utilized in vaccine delivery systems. Water-in-oil emulsions can directly prolong antigen presentation at the injection site as a result of the binding force between the antigen and droplet surface. The emulsion can also protect peptide antigens against degradation in the body fluids. ${ }^{142,143}$ As early as 1991, Tindle et al demonstrated that emulsification of $\mathrm{E}_{48-54}$ in CFA stimulated $\mathrm{T}$ cell proliferation and cytokine

Table 3 The Use of Immunological Adjuvants in Peptide-Based Nanovaccines Against Cervical Cancer

\begin{tabular}{|l|l|l|}
\hline Adjuvant Categories & Name and Composition & Mechanism \\
\hline Aluminum salts & AS04: Alum, MPL & TLR4 \\
\hline \multirow{2}{*}{ Emulsion-based adjuvant } & MF59: Squalene, Tween 80, Span 85 & Oil-in-water formulation \\
\cline { 2 - 3 } & IFA & Water-in-oil formulation \\
\hline \multirow{2}{*}{ Microbial derivative } & CPG-ODN & TLR9 \\
\cline { 2 - 4 } & Bacterial flagellin & TLR5 \\
\hline \multirow{2}{*}{ Lipid analogue } & Lipopeptide: Pam2Cys & TLRI/2 \\
\cline { 2 - 4 } & MPLA & TLR4 \\
\hline dsRNA analogue & Poly(I:C) & TLR3 \\
\hline Cytokine & GM-CSF & Immunostimulatory complexes \\
\hline
\end{tabular}


production in mice. ${ }^{116}$ Despite the excellent immunostimulatory properties of CFA, it contains heat-inactivated Mycobacterium bovis that can trigger obvious side effects, such as inflammation. ${ }^{144}$ Therefore, CFA is currently only used as a "gold standard" adjuvant in animal studies.

Montanide ${ }^{\mathrm{TM}}$ oil-based adjuvants based on incomplete Freund's adjuvant, which does not have M. bovis components, were broadly utilized in the formulation of peptide-based vaccines against cancers. ${ }^{145}$ For example, a vaccine formulation containing Montanide ISA 51, which was emulsified with PADRE Th epitope and the two CTL epitopes, HPV-16 E7 11-20 and E7 $86-93$, was tested in 19 HLA-A*0201-positive cervical cancer patients. ${ }^{131}$ The clinical Phase I-II trials showed no adverse effects of the formulation at three gradient doses. However, tumor regression was only observed in 4 of the 19 patients. ${ }^{131}$ Because all patients had advanced stages of cervical cancer, it was not possible to assess whether there was a specific immune response to the vaccine candidate.

\section{Toll-Like Receptor (TLR) Agonists Lipopeptides}

In recent decades, peptide antigens have often been mixed with or conjugated to lipid moieties to produce lipopeptides, which are PRR agonists that can target TLR1/2 (eg, dipalmitoyl-S-glyceryl cysteine (Pam2Cys)), TLR2/6 (Pam3Cys), and TLR2 (Pam2CSK4). ${ }^{132,142,146}$

As effective adjuvants, these lipopeptides were used in several studies to enhance the immunogenicity of peptidebased vaccines. For example, Moyle et al conducted tumor challenge studies on the synthetic bacterial lipopeptide adjuvant Pam2Cys conjugated to HPV-16-modified E7 protein $(\mathrm{E} 7 \mathrm{~m})$ to form a self-assembled vaccine candidate. Mice immunized with $25 \mu \mathrm{g}$ of Pam2Cys-E7 3 days after TC-1 cell tumor challenge showed slow tumor growth rate over 24 days. Mice immunized 7 days after the same tumor challenge displayed a $10 \%(1 / 10)$ survival rate after 60 days. ${ }^{147}$

Hussein et al developed lipoalkyne immunostimulant based on the Pam2Cys structure. Two epitopes derived from E6 and $\mathrm{E} 7$ proteins, $\mathrm{E} 6_{43-57}$ and $\mathrm{E} 7_{44-57}$, respectively, were conjugated together and acylated with a variety of double-chain lipid moieties. ${ }^{148}$ In particular, the most promising self-adjuvanting lipopeptide candidate $(450-750 \mathrm{~nm})$ conjugated with multi-antigens (E6 $43-57$ and $\left.\mathrm{E}_{44-57}\right)$ was able to trigger eradication of $46 \%(6 / 13)$ of 3-day-old tumors in mice. The lipopeptide candidate induced a higher survival rate compared to Pam2Cys analogue. ${ }^{148}$

Double-chain fluorinated lipid analogues were also tested as self-assembling adjuvants. HPV-16 E7 44-57 and E6 $6_{43-57}$ CTL epitopes were conjugated to fluorinated lipids and self-assembled into spherical particles $(10-15 \mathrm{~nm}) .{ }^{149,150}$ However, the fluorinated lipopeptides were unable to activate a strong CTL response against tumors. ${ }^{149}$

\section{Polyinosinic-Polycytidylic (Poly(l:C))}

TLR3 ligand poly(I:C), as a dsRNA analog, induced the production of IFNs, interrupting signal transmission from the innate immune response to adaptive immune response. ${ }^{151,152}$ A study by Wick et al demonstrated that HPV-16 E7 ${ }_{44-62}$ epitope adjuvanted with poly(I:C) stimulated CTL responses in immunized mice, but no immune response was observed with a short peptide E7 $49-57$ plus poly(I:C) formulation. Therefore, they concluded that precise CTL minimal epitopes are not the best vaccine strategy for immunization due to the limitation of HLA alleles and evasion from immunological pressure that can be oriented toward a single epitope. ${ }^{153}$

\section{Monophosphoryl Lipid-A (MPLA)}

TLR4 agonist MPLA was approved by the FDA and has been utilized in clinical trials as a potent adjuvant to enhance Th2, and to some extent Th1, immune responses. ${ }^{132}$ Jacoberger-Foissac et al conjugated CD4 epitope derived from HA influenza virus protein and CD8 epitope E7 ${ }_{49-57}$ from HPV-16 E7 protein to liposomes carrying one adjuvant: MPLA, TLR2/6 agonist S-[2,3-bispalmitoyloxy-(2R)-propyl]- $R$-cysteinyl-alanyl-glycine (Pam2CAG), or $\mathrm{NOD}_{1}$ agonist C12-iEDAP. C57BL/6J mice were challenged by TC-1 cells intravenously in the tail vein, followed by subcutaneous immunizations with liposomal vaccine containing $15 \mu \mathrm{g}$ of E7 $7_{49-57}$ on days 2 and 4 . Based on tumor lung nodule counts after 28 days, all three adjuvants were effective in inducing specific immune responses and eliminating tumors. ${ }^{132}$ 


\section{Bacterial Flagellin}

The utilization of bacterial flagellin dates back to 1960. Flagellin is an effective agonist that binds to TLR5, stimulating innate and adaptive immunity. ${ }^{154,155}$ Nguyen et al demonstrated that flagellin, particularly $V$. vulnificus FlaB, could be used as a potent adjuvant in peptide-based vaccines against cervical cancer. ${ }^{123}$ In this study, the CTL peptide epitopes HPV-16 E6 $50-57$ and E7 $49-57$ were administered with bacterial flagellin adjuvant to mice, resulting in the secretion of a large amount of IFN- $\gamma$. A peptide-specific CLT immune response was stimulated and the infinite proliferation of tumor cells controlled. Ultimately, the vaccine regulated the growth of malignant cells in the cervix and prevented lung metastasis.

\section{Synthetic ODN-CpG}

Synthetic oligodeoxynucleotides (ODNs), consisting of unmethylated CpG motifs, can complex with TLR9, affecting an innate immune response based on the stimulation of Th1 and the secretion of inflammatory cytokines, including IL-10, IL-4, IL-2, IFN- $\gamma$, and co-stimulatory molecules. ${ }^{139} \mathrm{ODN}-\mathrm{CpG}$ is the most popular and effective immunostimulatory adjuvant for cellular immune responses and it is widely used as a component of anticancer vaccines. ${ }^{156,157}$

CpG-ODN 1826 (5'-TCCATGACGTTCCTGACGTT-3')-based vaccine carrying mixed E5 25-33 peptide antigen induced E5-specific CTL activity and tumor regression that surpassed even the positive control containing CFA in a C57BL/6 mouse model challenge with TC-1 tumor cells. ${ }^{158}$ In another study, Yang et al assessed the singleimmunization efficacy of a series of vaccine candidates (10,30 and $50 \mu \mathrm{g}$ of E7-derived peptides in a mixture with ODNCpG 1826) in 3-day-old tumors in C57BL/6 mice challenged with TC-1 cells. All mice immunized with long peptide HPV-16 E7 $43-77(50 \mu \mathrm{g}) / \mathrm{ODN}-\mathrm{CpG} 1826$ showed complete tumor eradication. However, there was no significant difference in tumor size between the groups immunized with long peptide E743-77, or short peptide E7 $7_{49-57}$ in a mixture with ODN-CpG $1826 .{ }^{159}$

\section{Nanoparticle-Based Vaccines}

Nanoparticles are a specific and efficient delivery platform for peptide antigens to enhance immunogenicity and stability. Physical parameters of nanoparticles, including size, shape, and surface properties, can be relatively easily manipulated to affect the immune responses generated against the associated antigen. ${ }^{17,18,160}$ Typically, the immune system recognizes nanoparticles $(<1 \mu \mathrm{m})$ with a pattern similar to that of pathogens. Small nanoparticles $(20-200 \mathrm{~nm})$ can enter the lymphatic system on their own and travel to the lymph nodes. DCs readily take them up through endocytosis. In contrast, $0.5-5 \mu \mathrm{m}$ particles are more likely to be taken up by phagocytosis by DCs and macrophages and need active transport (via APCs) to reach the lymph nodes. ${ }^{161-163}$

The approach of nanostructure construction in peptide-based vaccines is a significant factor controlling antigen retention and vaccine immunogenicity. ${ }^{164}$ Nanoparticles typically possess immune-stimulating properties that trigger antigen delivery and more robust APC recognition and uptake. ${ }^{165}$ Furthermore, antigens formulated into or entrapped in nanoparticles can avoid enzymatic degradation. Nanoparticles remain in the body for longer and are more permeable across barriers, including mucosal tissues. ${ }^{160,162}$

Antigens can be physically mixed with nanoparticles or incorporated into them by adsorption, encapsulation, chemical conjugation, and self-assembly (Figure 5). ${ }^{162,165}$ Physical mixture is the simplest nanoparticle manufacture method. It is achieved by agitation of two different dispersed phases in an organic substance without significant interactions between particles and antigens. Peptide-based vaccine candidates mixed in this way are characterized by a weak attachment of antigens and nanoparticles and low immunogenicity. ${ }^{166}$ Adsorption is based on charge and/or hydrophobic affinity between the peptide antigen and nanoparticle material, making antigen adhesion to nanoparticles weak; this often results in rapid antigen disassociation after injection. ${ }^{162,167}$ Encapsulation and chemical conjugation more strongly associate antigens with nanoparticles, enhancing their stability in vivo. ${ }^{162}$ In encapsulation, the target antigen is encapsulated inside the nanoparticle and gradually released in vivo, preferably at specific sites, efficiently avoiding enzymatic degradation. Conjugation is based on the formation of a chemical bond between antigen nanoparticles - antigens are often exposed on the surface of nanoparticles. Finally, antigens can also be modified to enable selfassembly of nanoparticles. Self-assembly refers to the spontaneous arrangement of molecules through non-covalent 


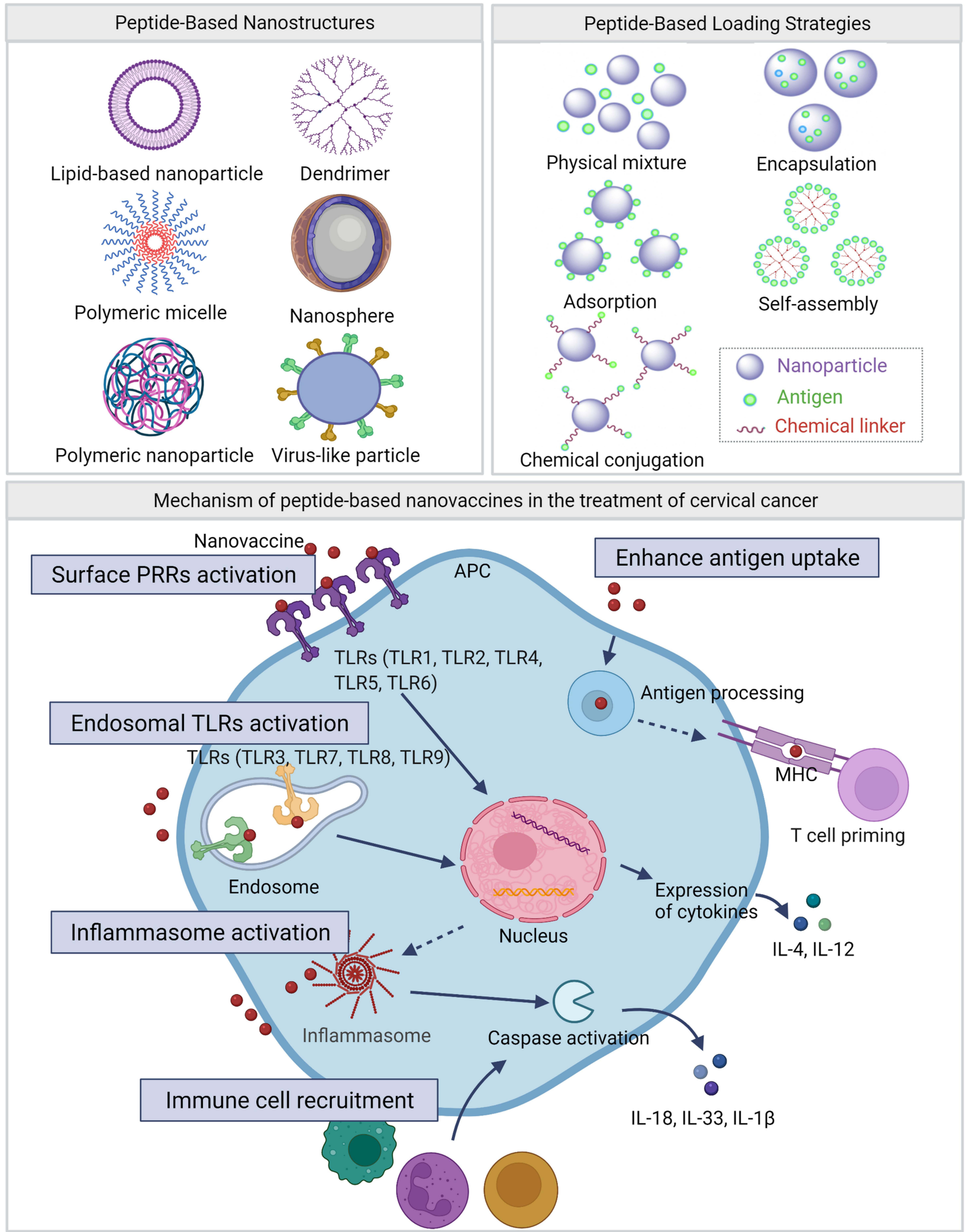

Figure 5 Different peptide-based nanostructures, loading strategies and mechanism. Peptide-based nanostructures include lipid-based nanoparticle, dendrimer, polymeric micelle, nanosphere, polymeric nanoparticle and virus like particle. Peptide-based loading strategies include physical mixture, encapsulation, adsorption, self-assembly and chemical conjugation. Mechanisms of peptide-based nanovaccines in the treatment of cervical cancer include surface pattern recognition receptors (PRRs) activation, endosomal TLRs activation, inflammasome activation, immune cell recruitment and enhance antigen uptake. 
interactions guided by internal and external factors, such as hydrophilic to hydrophobic ratio, molecular conformation, and environmental conditions, resulting in an ordered nanostructure. ${ }^{165,168}$

\section{Polymeric Nanoparticles}

As flexible materials, polymers comprise protracted and repeating chains of molecules. ${ }^{169,170}$ Polymers can be conjugated with epitopes to protect them from enzymatic degradation, control the release of antigens at a specific site, and enhance the immunogenicity of peptide-based vaccines. ${ }^{162,171}$ Both natural and synthetic polymers have been extensively explored and utilized for vaccine delivery, mainly when used in the form of nanoparticles. ${ }^{167}$

\section{Naturally Occurring Polymeric Nanoparticles}

The most widely used natural polymers are polysaccharides, such as chitosan, inulin, alginate, pullulan, dextran, and hyaluronic acid. ${ }^{140,172}$ Among them, chitosan is the most commonly used natural polymer with adjuvant properties, as it has mucosa adhesive properties, excellent permeability, biocompatibility, and biodegradability, in addition to being low cost and broadly available. ${ }^{162,173,174}$ Chitosan is prepared from chitin, which is the paramount compound from crustacean and fungal cell walls. It is obtained by a chemical reaction of basic deacetylation of chitin composed of $\beta$-(1-4)-chain copolymer of D-glucosamine and $N$-acetyl-D-glucosamine. ${ }^{142,173}$ Chitosan and its derivatives are usually used in vaccine formulations as polyelectrolyte-based nanoparticles. ${ }^{175}$ Generally, antigens encapsulated in chitosan particles can stimulate macrophages and DCs, which can migrate to lymph nodes, enhancing cellular and humoral immune responses in vivo. ${ }^{176}$ Chitosan particles can be modified into subcellular-sized nanoparticles for mucosal administration due to their mucoadhesive properties. ${ }^{142,176}$ However, the low solubility of chitosan reduces its utility, and the formation of nanoparticles requires harsh acidic conditions. To overcome this, various chitosan derivatives have been produced, including $N$-trimethylated chitosan (TMC), mono- $N$-carboxymethyl chitosan (MCC), and glycated chitosan (GC): these significantly enhance efficacy. ${ }^{142,177}$

\section{Synthetic Polymeric Nanoparticles}

Synthetic polymer-based particles, including poly(D, L-lactide-co-glycolide; PLG), poly( $\gamma$-glutamic acid; $\gamma$-PGA), poly(D, L-lactic-co-glycolic acid; PLGA), poly(ethylene glycol; PEG), and polyacrylates, have become the main object of extensive research for the manufacture of peptide-based vaccines. ${ }^{162}$ PLGA, as an aliphatic polyester, is estercarboxylic acid-terminated and comprises different ratios of both lactic and glycolic acid. ${ }^{169}$ PLGA was approved by the FDA and is often used for peptide-based vaccine delivery. ${ }^{178,179}$ Peptide antigens can be encapsulated inside or adsorbed on the surface of PLGA nanoparticles to protect the antigen from degradation or dissolution before it is taken up by APCs. ${ }^{180,181}$ Moreover, PLGA allows for slow release of the antigen from nanoparticles, regulating antigen exposure time to the adaptive immune system. ${ }^{178}$ Controlled antigen release directly affects DCs and enhances $\mathrm{CD} 8^{+}$and $\mathrm{CD}^{+}$immune responses in humans. Antigen release rate can also be controlled by modification of PLGA composition, particle size, particle surface porosity of the matrix, and antigen loading approaches. ${ }^{178}$ The co-delivery of TLR agonists and antigens by PLGA nanoparticles can enhance cellular immunity and implement the therapeutic approach against cervical cancer. ${ }^{178}$ However, some drawbacks of PLGA as a peptide delivery system have emerged: the acidic microenvironment formed during PLGA degradation causes amide bond hydrolysis, deamidation, and oxidation of the peptide, which triggers unfolding or aggregation of the peptide chain. ${ }^{182}$ Thus, PLGA-entrapped peptide/protein suffers from unpredictable side effects that affect its immunogenicity and toxicity.

Recently, Zhang et al developed a therapeutic HPV nanovaccine candidate with PLGA encapsulating HPV-16 E7 $44-62$. Within the design, they introduced adenosine triphosphate (ATP) as a new adjuvant component. ${ }^{183}$ The formed nanoparticles (about $300 \mathrm{~nm}$ ) completely inhibited tumor growth in mice (10/10) after 49 days of TC-1 implantation, compared to $60 \%$ (6/10) tumor elimination for E7 $44-62$-PLGA. For the tumor challenge assay, E7 $44-62$-PLGA had a $60 \%$ survival rate after 92 days, while E7 $7_{4-62}$-PLGA plus ATP resulted in $100 \%$ survival in mice. In conclusion, the encapsulation of PLGA enhanced the presentation of antigen to APCs and stimulated the onset of the immune response, as well as ATP-induced DC maturation, and enhanced antigen recognition and uptake by DCs. 
Rahimian et al constructed a vaccine candidate based on a hydrophilic polyester, poly(D, L-lactic-co-hydroxymethyl glycolic acid) (pLHMGA), which was based on lactic acid and glycolic acid with pendant hydroxyl groups. ${ }^{184}$ In the delivery system, pLHMGA loaded HPV-16 E7 $43-69$, which was co-delivered with the TLR3 ligand, poly (I:C). ${ }^{184}$ Using the double emulsion solvent evaporation technique, nanoparticles with a size of 400-500 nm and PDI of 0.20-0.29 were prepared. The nanoparticles had a significant inhibitory effect on TC-1 tumor size in challenged C57BL/6 mice, induced a substantial increase in the number of $\mathrm{HPV}$-specific $\mathrm{CD} 8^{+} \mathrm{T}$ cells, and prolonged mouse survival time by three weeks, but failed to eradicate the tumors. ${ }^{184}$ In addition, the study demonstrated that pLHMGA has high biodegradability and safety profile.

Polyacrylate is a widely used colloidal drug carrier polymer, particularly poly(acrylic acid), and its ester analogs are easy to be synthesized and have little or no toxicity. ${ }^{185}$ As an amphiphilic dendrimer structure, polyacrylate polymer can self-assemble nanoparticles with the desired size while loading antigenic epitopes. ${ }^{186}$ Liu et al conjugated HPV-16 E744-57 antigen to polyacrylate star-polymers with different branching levels and self-assembled them into microparticles. ${ }^{187}$ Mice bearing TC-1 tumors (3-day-old) were immunized with polymers bearing 1, 2, 4, and 8 copies of the epitope. The conjugates $(12-17 \mu \mathrm{m})$ eliminated E7-positive TC-1 tumors upon single-dose immunization without adjuvant, and survival rates (up to 90\%) were higher than the positive control group (IFA-adjuvanted antigen, $40 \%$ ). ${ }^{187}$ It was also found that $8 \mathrm{Q}_{\mathrm{min}}$-dendritic polymer, bearing eight copies of the epitope, was quickly taken up by antigenpresenting cells and elicited strong CD $8^{+}$cell responses without triggering TLR2 activation. ${ }^{188,189}$ Depletion studies with anti-CD4 ${ }^{+}$, anti-CD8 ${ }^{+}$, and anti-NK antibodies showed that vaccine efficacy was strictly related to CTL activation. ${ }^{188}$ When mice bearing more advanced tumors (7-day-old) were immunized, the efficacy of the vaccine dropped drastically to $20-50 \%$ survival after 90 days; ${ }^{121}$ however, it was restored once the $8 \mathrm{Q}_{\mathrm{min}}$-dendrimer conjugate was formulated into liposomes ( $80 \%$ survival rate), effectively reducing the particle size from micrometers (about $15 \mu \mathrm{m}$ ) to nanometers (about $140 \mathrm{~nm}$ ). ${ }^{190}$ In contrast, when particle size was controlled by modification of polyacrylate with poly(glutamic acid), the nanoparticles (about $430 \mathrm{~nm}$ ) failed to improve conjugate efficacy. ${ }^{191}$

Amidi and coworkers reported that the application of thermosensitive polymer, poly( $N$-isopropyl acrylamide) (pNIPAm), conjugated to HPV-16 E7 $7_{43-57}$ developed a self-assembling nanovaccine with particle diameter of about $200 \mathrm{~nm} .{ }^{192}$ They also studied in-depth short amphiphilic peptide SA (Ac-AAVVLLLW-COOH) as self-assembling nanovesicular structures based on hydrophobic clustering and an intermolecular hydrogen bond. In addition, they synthesized poly( $N, N$-dimethyl acrylamide) (pDMAm) by polymerization reaction as a control and added CpG ODN 1826 as a supplemental adjuvant to compare in vivo antigen cross-presentation as well as tumor control. The results showed that $\mathrm{CpG}$ adjuvant complemented the particle delivery system to enhance antigen cross-presentation and improve $\mathrm{CD}^{+} \mathrm{T}$ cell responses. In the TC-1 tumor model, the combination of HPV-pNIPAM plus CpG and HPV-SA plus CpG delayed tumor growth and prolonged survival in mice $(p<0.0005 ; p<0.05)$, whereas neither the formulation without adjuvant nor the particle delivery system was adequate for HPV tumors.

Gao's group developed an ultra $\mathrm{pH}$-sensitive nanoprobe with a sharp $\mathrm{pH}$ response, PC7A, consisting of a copolymer of tertiary amines with a cyclic side chain. ${ }^{193,194}$ It was physically mixed with antigen to form nanoparticles (20-50 nm) that could facilitate the presentation of tumor antigen and activate type I stimulator of interferon genes (STING), rather than the TLR receptor pathway. ${ }^{194}$ In the HPV TC-1 tumor model, E7 $43-62$-PC7A achieved tumor elimination in up to $50 \%$ of tumor-bearing mice after 60 days of treatment. In contrast, the combination of E7 $43-62$-PC7A with anti-PD-1 antibody resulted in $100 \%$ survival of mice implanted with TC-1 tumors after 60 days, and $90 \%$ of mice were tumorfree. ${ }^{194}$ Similarly, the combination of this vaccine candidate with radiation therapy improved the increase in $\mathrm{CD} 8^{+} \mathrm{T}$ cells of tumor-bearing mice and achieved better effects in distal tumors. ${ }^{195}$

\section{Liposome Nanoparticles}

Alec Bangham first observed that phospholipids could form bilayer structures in aqueous solutions; these were named liposomes. Liposomes have been extensively used in drug and vaccine formulations due to their significant biocompatibility, low toxicity, potent loading capacity, and controlled-release kinetics. ${ }^{196}$ Liposomes are one of the predominant adjuvants for peptide-based vaccines against infectious diseases. They comprise hydrated phospholipids as one or more bilayer structures, with polar groups oriented towards both the inner and outer aqueous phase. ${ }^{197}$ Liposomes can encapsulate bioactive hydrophilic, hydrophobic, and amphiphilic molecules within the inner aqueous phase or lipid 
bilayers, generally protecting cargo from degradation, but also allowing its targeted delivery. ${ }^{196-198}$ The properties of liposomes can be controlled by modification of their charge, size, lamellarity, and composition, including incorporation of cell-specific targeting moieties. ${ }^{142,196,199,200}$

Cationic liposomes are popular carriers of antigenic peptides, rather than anionic or neutral liposomes, due to their ability to be preferentially taken up by APCs. ${ }^{142}$ 1,2-dioleoyl-3-trimethylammonium propane (DOTAP)/E7 $49-57$ liposome (with $100 \mathrm{~nm}$ of DOTAP and $10 \mu \mathrm{g}$ of E7 ${ }_{49-57}$ ) possessed the ability to activate DCs, stimulate antigen-specific CTLs, and significantly inhibit 6-day-old tumor growth on day 24 in vivo. It was found that DOTAP activated MAP kinase ERK and the p38 pathway in DCs, via triggering of chemokine and cytokine production. ${ }^{201}$ After 6 days of TC-1 tumor inoculation, a single dose of cationic DOTAP (75 and $150 \mathrm{nmol} /$ mouse) and liposomes encapsulating HPV-16 E7 $49-57$ (10 $\mu \mathrm{g} /$ mouse) showed significant tumor regression $(\mathrm{P}<0.001$ and $\mathrm{P}<0.01$, respectively) compared to untreated mice on day $23 .{ }^{202}$ Further, to enhance the incorporation of DOTAP and E7 $49-57$ peptide, lipid modification of E7 $49-57$ was performed through an extended KSS linked to palmitic acid. The lipopeptide modification enhanced antigen-specific CTL response in vivo compared to the simple DOTAP/E7 formulation. ${ }^{203}$

Vasievich et al demonstrated that not only charge but also chirality of DOTAP can play an essential role in liposomes' anti-tumor potency, as $R$-DOTAP isomer has more potent immune-stimulating capacity. ${ }^{204}$ Recently, the Lovell group constructed liposomes consisting of cobalt-porphyrin-phospholipid (CoPoP), P-HAD-3D6A (a synthetic derivative of MPLA), HPV E7 49-57, and QS-21 (saponin-based adjuvant), admixing with HPV-16 E7 $49-57 .{ }^{205}$ The vaccine candidates $(100 \mathrm{~nm})$ were more effective in inhibiting tumor growth than poly(I:C) mixed with antigen. Unfortunately, after effectively shrinking the rapidly growing tumors, TC-1 tumors regrew in mice after 8 days, and the number of $\mathrm{CD} 8^{+}$ T cells maintaining tumor dissipation was low. Further immune-boosting and stability studies are needed for this vaccine candidate.

In recent years, a vaccine delivery platform named $\operatorname{VacciMax}^{\circledR}(\mathrm{VM})$ enclosed antigen sequences and adjuvants in multilamellar liposomes in a water-in-oil emulsion. ${ }^{206}$ HLA-A2 transgenic mice of advanced age (48-58 weeks old) harboring large palpable TC1/A2 tumors were used to investigate the therapeutic potential of VM-based vaccinations. One or more peptides with human CTL epitopes derived from HPV 16 E6 and E7 proteins were included in the VMbased vaccinations. A single peptide, a combination of four peptides, or the same four peptides joined together in a single long peptide, were used in the formulations. Th epitope, PADRE, and $\mathrm{CpG}$ adjuvant were incorporated in all VM formulations, and ISA 51 was used as the hydrophobic ingredient of the water-in-oil emulsion. Within 21 days of single immunization, VM-formulated vaccines containing the four peptides as a physical mixture or joined together in one continuous peptide eliminated 19-day-old established tumors. ${ }^{206}$

In similar studies, HPV-16 E7 $49-57$ peptide and adjuvant were solubilized in suitable buffer and mixed with a 10:1 (w:w) DOPC/cholesterol mixture to produce liposome formulations called DepoVax ${ }^{\mathrm{TM}}$ (DPX). ${ }^{207,208}$ Prior to injection, the aqueous mixture was lyophilized into a dry cake that was reconstituted directly in oil, such as Montanide ISA 51. When administered in a treatment protocol, preclinical testing of DPX-based vaccines demonstrated that they were efficient in reducing tumor growth. ${ }^{208}$ These vaccinations produce antigen-specific T lymphocytes, which could be detected in the circulation and in the tumor microenvironment. ${ }^{207}$ Combining DPX with additional immune therapies, like metronomic cyclophosphamide (mCPA) and anti-PD-1, can boost the active immunological responses elicited by DPX. ${ }^{207,208}$ For example, female C57BL/6 mice (10 per group) were challenged with a murine tumor model expressing HPV-16 E7. Compared to mice treated with DPX-E7 $49-57 / \mathrm{mCPA}$ immunotherapy, mice treated with anti-PD-1 in combination with DPX-E7 $7_{49-57} / \mathrm{mCPA}$ immunotherapy experienced a considerable delay in tumor growth and a significant increase in survival. Similar results were achieved utilizing two other tumor models, B16-F10 and HLA-A2 ${ }^{+}$ovarian tumors. ${ }^{207}$

\section{Virus-Like Particles}

Virus-like particles (VLPs) contain several recombinant viral structural proteins. Lacking viral genomes, VLPs cannot induce replication and infection. However, they can easily deliver cargo into the APCs. VLPs range in size from 20 to $200 \mathrm{~nm}$ in diameter and share viruses' ability to stimulate Th1 and CTL immune responses, similar to intracellular/ endogenous antigens. ${ }^{142,209}$ Exogenous antigens preferentially enter the MHC II pathway and interact with $\mathrm{CD}^{+} \mathrm{T}$ cells, whereas VLPs can be cross-presented and bind to MHC I molecules, eventually inducing a potent $\mathrm{CD} 8^{+}$immune 
response against infectious diseases, especially cancers. ${ }^{142,210}$ VLPs, similar to other protein products, can be produced in a variety of cells, including bacterial, insect, plant, yeast, and mammalian cell lines. Antigen can be incorporated into VLPs by genetic engineering prior to protein expression or by conjugation to the expressed VLP by chemical coupling. As a nanoscale adjuvant, VLPs have been used in a wide range of vaccine candidates against various infectious diseases due to their immunogenicity, safety and efficacy. ${ }^{211}$

As early as 1997, Müller et al constructed a chimeric VLP (cVLP) consisting of the HPV-16 L1 major coat protein, expressed to form an empty protein coat, and incorporated E7 $1-60 .{ }^{212}$ The cVLP reached the MHC I pathway through cytoplasmic and endoplasmic reticulum processing. Without adjuvant stimulation, cVLP showed the ability to induce cytotoxic immune responses and specific tumor protection. ${ }^{213}$ The cVLP was proven safe in clinical trials and triggered specific cellular immunity against E7, but histological improvement was observed in only $39 \%$ of patients. ${ }^{210,214}$ Freyschmidt et al studied how HPV-16 L1/E7 cVLPs interacted with mouse bone marrow-derived dendritic cells (BMDCs) that were stimulated with various immunological adjuvants. ${ }^{215}$ cVLP-induced activation of C57BL/6 mice BMDCs was augmented by lipopolysaccharides (LPS), unmethylated CpG motifs (CpG ODN), and sorbitol, as shown by elevated levels of CD40, CD80, MHC II, and CD54 on the cell surface. After loading cVLPs onto BMDCs, CpG ODN and sorbitol improved the presentation of $\mathrm{D}^{\mathrm{b}}$-restricted cytotoxic $\mathrm{T}$ lymphocyte epitopes to HPV-16 L1- or E7-specific $\mathrm{T}$ lymphocytes. In vitro priming of naive T lymphocytes by cVLP-loaded BMDCs was improved through treatment with CpG ODN in combination with cVLPs. In comparison to cVLP injection alone, cVLP-loaded BMDCs were more immunogenic in vivo. Antigen-specific T cell responses were further improved by $\mathrm{CpG}$ ODN and sorbitol, indicating that BMDCs stimulated with CpG ODN, or sorbitol can significantly improve the immunogenicity of cVLPs. ${ }^{215}$

Monroy-Garcia et al designed an HPV-16 L1 cVLP (about $50 \mathrm{~nm}$ ) produced from tomato plants fused with E6 $6_{16-30}$, $\mathrm{E} 7_{37-54}, \mathrm{E}_{49-57}$, and $\mathrm{E} 7_{86-93}$ epitopes. In vivo tumor suppression assays demonstrated a significant $57 \%$ tumor reduction in 2-week-old TC-1 tumor-bearing mice after immunization with three doses of cVLP administered at 2-week intervals. ${ }^{216}$

Jemon et al developed a heterologous rabbit hemorrhagic disease virus (RHDV)-based VLP vaccine, E6-RHDV-VLPPADRE, containing both Th epitope PADRE and CTL epitope HPV-16 E6 $48-57$. After two immunizations 1 week apart, it reduced pre-existing 9-day-old TC-1 tumors by $50 \%$ and doubled survival time compared to the control group in C57BL/6 mice (8 per group). ${ }^{217} \mathrm{HPV}-16 \mathrm{E}_{45-98}$ was embedded in infectious bursal disease virus (IBDV) VLPs, to obtain the VLPE7 construct (around $45 \mathrm{~nm}$ ). In HLA-A2 humanized transgenic C57BL/6 mice (7 per group), one single dose vaccine achieved a $100 \%$ survival rate for up to 4 months in preclinical trials, with complete eradication of 9-day-old TC-1 tumors. Results persisted, even when mice were rechallenged with TC-1/A2 tumor cells on day $56 .{ }^{218}$

Hepatitis B virus core antigen ( $\mathrm{HBcAg}$ ) can also efficiently self-assemble into VLPs in Escherichia coli cells, resulting in a vaccine carrier, HBcAg VLP. Chu et al demonstrated that HBcAg VLP presenting the HPV-16 E7 $49-57$ epitope successfully stimulated specific cellular immunity and sustained effective antitumor memory cells, which was validated by the significant elevation of IFN- $\gamma$ in splenocytes. ${ }^{219}$ In treatment tests, three doses of VLP immunization dramatically slowed tumor progression in mice with TC-1 tumors as small as $2-3 \mathrm{~mm}$ in diameter and as large as $8-$ $9 \mathrm{~mm}^{219}$

Recently, Gomes et al chemically linked E7 $49-57$ oligomers to Q $\beta$ phage VLPs loaded with non-methylated CG motifs (CpGs) as adjuvant. ${ }^{220}$ Mice were injected with TC-1 cells expressing the HPV16 E7 oncoprotein in order to examine the therapeutic capacity of vaccine-induced T cells. Mice developed palpable tumors 8 days after receiving tumor cells and were administered $\mathrm{E} 7$ linked or mixed to $\mathrm{Q} \beta$ on a weekly basis for 49 days. Half (50\%) of untreated mice, as well as those injected with $\mathrm{Q} \beta$ alone, were euthanized by day 32 with tumor size larger than $1,000 \mathrm{~cm}^{3}$. In contrary, both the linked and mixed formulations of $\mathrm{Q} \beta$ and $\mathrm{E} 7$ protein were able to produce substantial tumor growth suppression, resulting in a survival rate of over $80 \%$ at the end of the study. Thus, covalent attachment of E7 to Q $\beta$ VLPs is not necessary for the activation of therapeutic $\mathrm{T}$ cell responses against solid tumors. ${ }^{220}$

\section{Granulocyte-Macrophage Colony-Stimulating Factor as an Adjuvant}

Granulocyte-macrophage colony-stimulating factor (GM-CSF) is a hematopoietic growth factor and immune modulator that can affect the function of circulating leukocytes. T cells, macrophages, endothelial cells, and fibroblasts are among 
the cell types that produce GM-CSF in response to immunological stimuli. ${ }^{221}$ GM-CSF can be applied as an immune adjuvant of low toxicity for anticancer peptide-based vaccine development. ${ }^{221,222}$ Additionally, GM-CSF can control the secretion of various inflammatory cytokines, including IL-1, IL-6, IL-12, TNF- $\alpha$, INF- $\gamma$, IgF2a, and IL-1 $\beta{ }^{151,221}$ Tang et al designed a self-assembled peptide-based nanovaccine, Tat-E7/pGM-CSF, consisting of HPV-16 E7 $7_{49-57}$ as a CTL epitope, fused with the cell-penetrating peptide HIV-1 Tat ${ }_{49-57}$ to form a cationic fusion peptide. They then mixed it with a negatively charged plasmid expressing GM-CSF from mice to create nanoparticles with a diameter of $20-80 \mathrm{~nm} .{ }^{223} \mathrm{In}$ mice, Tat-E7/pGM-CSF produced enhanced E7-specific T cell responses. Administration of Tat-E7/pGM-CSF on days 3 and 10 after TC-1 tumor inoculation to C57BL/6 mice (10 per group) showed controlled tumor cell growth and a survival rate of $80 \%$ at 70 days. ${ }^{223}$

\section{Clinical Trials of Peptide-Based Vaccines Against Cervical Cancer}

This review classifies clinical trials into two categories: (1) peptide-based vaccines as a single therapy, and (2) combination therapy of peptide-based vaccines and other treatments. We describe the most representative trials from the past decade (Table 4).

\section{Peptide-Based Vaccines in Clinical Trials}

Many peptide-based therapeutic HPV vaccines have been found to be safe and well tolerated in early phase I-II clinical trials. For example, peptide-based vaccine comprised long peptide sequences bearing E7 11-20 and E7 $86-93$, linked to Th epitope PADRE was emulsified in Montanide ISA 51 adjuvant and injected into HPV-16-positive cervical carcinoma patients. ${ }^{131}$ Nineteen patients were divided into three groups and injected with $100 \mu \mathrm{g}, 300 \mu \mathrm{g}$, or $1000 \mu \mathrm{g}$ of each peptide in this dose-escalation study. ${ }^{131}$ None of the patients reported experiencing any severe adverse effects. Fifteen individuals developed progressive disease, whereas two patients, who additionally received chemotherapy after vaccination, experienced tumor regression. In a similar phase I-II clinical trial, fifteen patients with HLA-A*0201 HPV-16 cervical cancer received comparable vaccines. Among them, 4 patients had significant PADRE T helper peptide-specific proliferation, but none showed an HPV-specific CTL response. ${ }^{130}$ Another Phase I clinical trial was conducted in 18 female patients with high-grade cervical or vulvar intraepithelial neoplasia. All patients received HPV-16 E7 ${ }_{12-20}$ peptide mixed with Montanide ISA 51 or lipopeptide consisting of linker peptide (KSS), Th epitope PADRE, and E7 $86-93 .{ }^{129}$ The therapeutic vaccine formulations were rather harmless: 17/18 patients developed grade I or II local responses and/or granuloma development, including erythema, edema, and warmth three weeks following immunization. HPV E7-specific $\mathrm{T}$ cell immunity was detected in peripheral blood mononuclear cells in 10 patients. ${ }^{129,224}$

Another Montanide ISA 51-adjuvanted vaccine, HPV-16 SLP (ISA 101), was composed of 13 overlapping peptides $\left(\mathrm{E} 6_{1-32}, \mathrm{E} 6_{19-50}, \mathrm{E} 6_{41-65}, \mathrm{E} 6_{55-80}, \mathrm{E} 6_{71-95}, \mathrm{E} 6_{85-109}, \mathrm{E} 6_{91-120}, \mathrm{E} 6_{127-158}, \mathrm{E} 7_{1-35}, \mathrm{E} 7_{22-56}, \mathrm{E} 7_{43-77}\right.$, and $\left.\mathrm{E} 7_{64-98}\right)$, representing the entire sequence of HPV-16 E6 and E7. It has been through numerous clinical phase I-II studies. ${ }^{225-229}$ The long peptides effectively delivered the antigen to DCs, eliciting HPV-16-specific CD4 ${ }^{+}$and $\mathrm{CD} 8^{+} \mathrm{T}$ cell responses. They had minimal toxicity and sustained immunogenicity in patients with advanced cervical cancer after vaccination in a phase I clinical trial. ${ }^{225}$ To evaluate the toxicity, safety, and immunogenicity of isolated or combined HPV-16 E6 and E7 synthetic peptide vaccines, 35 patients with advanced cervical cancer were split into three groups and vaccinated with Montanide ISA 51 adjuvant. Group 1 received $300 \mu \mathrm{g}$ of synthetic peptide in one arm; Group 2 received $100 \mu \mathrm{g}$ of E6 peptide in one arm and $300 \mu \mathrm{g}$ of E7 peptide in the other arm; and Group 3 received $50 \mu \mathrm{g}$ of both E6 and E7 peptides. No hazardous responses above grade 2 were reported during or after the four vaccine doses. The combination of E6 and E7 peptides elicited a robust and broad-spectrum T-cell response, as determined by ELISPOT analysis. Inoculation of E6 and E7 peptides at distinct sites enhanced the immune response to E7 but had no impact on the immunological response induced by E6. HPV-16 E6 and E7 SLP were well tolerated and induced a broad IFN-associated T-cell response in patients with advanced cervical cancer. In the following year, Kenter et al reported clinical responses to HPV-16-specific T cells in a Phase II trial in 20 women with HPV-16-positive grade 3 vulvar intraepithelial neoplasia. ${ }^{226}$ Three months after vaccination, $60 \%$ of the patients experienced clinical responses and reported symptom resolution, with four patients experiencing complete regression and no HPV-16 presence. 
Table 4 Clinical Trials of Peptide-Based Vaccines Against Cervical Cancer

\begin{tabular}{|c|c|c|c|c|c|}
\hline Vaccine & $\begin{array}{l}\text { Vaccine Composition \& } \\
\text { Adjuvant }\end{array}$ & Phase/ Status & Clinical Trials & Outcomes & Ref \\
\hline \multirow[t]{2}{*}{ HPV-16 E7 II-20/86-93, peptide trial } & \multirow[t]{2}{*}{$\begin{array}{l}\mathrm{HPV}-16 \mathrm{E7}_{\mathrm{II-20}}, E 7_{86-93} \text { and } \\
\text { PADRE emulsified in Montanide } \\
\text { ISA } 5 \text { I adjuvant }\end{array}$} & I-II/ Completed & $\begin{array}{l}19 \text { patients; dose- } \\
\text { escalation study }\end{array}$ & $\begin{array}{l}15 \text { patients developed } \\
\text { progressive disease; } 2 \\
\text { patients showed tumor } \\
\text { regression with } \\
\text { chemotherapy. }\end{array}$ & {$[|3|]$} \\
\hline & & I-II/ Completed & 15 patients & $\begin{array}{l}\text { No HPV-specific CTL } \\
\text { response. }\end{array}$ & [130] \\
\hline HPV-I6 E7 $12-20 / 86-93$ peptide trial & $\begin{array}{l}\text { HPV- } 16 \mathrm{E7}_{\mid 2-20}, \mathrm{E7}_{86-93} \text {, and } \\
\text { PADRE emulsified in Montanide } \\
\text { ISA } 5 \text { I adjuvant }\end{array}$ & I/ Completed & $\begin{array}{l}18 \text { patients; dose- } \\
\text { escalation study }\end{array}$ & $\begin{array}{l}10 \text { patients showed HPV- } 16 \\
\text { E7 specific CTL response. }\end{array}$ & [129] \\
\hline $\begin{array}{l}\text { Five peptides for HLA-A*2402 } \\
\text { cervical cancer }\end{array}$ & $\begin{array}{l}\text { Five peptides: FOXMI-262, } \\
\text { MELK-87-7N, HJURP-408, } \\
\text { VEGFR-I-1084 and VEGFR-2-169 } \\
\text { in Montanide ISA } 51 \text { adjuvant }\end{array}$ & I/ Completed & $\begin{array}{l}\text { UMIN000003999: } 9 \\
\text { patients; dose- } \\
\text { escalation study }\end{array}$ & $\begin{array}{l}\text { No toxicity and well- } \\
\text { tolerated }\end{array}$ & [230] \\
\hline WT-I peptide trial & $\begin{array}{l}\text { WT-I }{ }_{187-195}, \text { GM-CSF, Montanide } \\
\text { ISA } 51 \pm \text { CpG7909 }^{-}\end{array}$ & I/ Completed & $\begin{array}{l}\text { UMIN00000277I: } 28 \\
\text { patients; } 2 \text { groups }\end{array}$ & $\begin{array}{l}\text { Skin toxicity level and } \\
\text { adverse effects }\end{array}$ & [231] \\
\hline \multirow[t]{2}{*}{ PI637-63 peptide trial } & $\begin{array}{l}\text { p1637-63 peptide of cellular } \\
\text { protein } \mathrm{PI} 6^{\text {INK4 }} \text { plus Montanide } \\
\text { ISA-5I adjuvant }\end{array}$ & I-Ila/ Completed & $\begin{array}{l}\text { NCT0I462838: } 26 \\
\text { patients; single group; } \\
\text { open label }\end{array}$ & No dose-limited toxicity & [234] \\
\hline & $\begin{array}{l}\text { Cisplatin-based chemotherapy } \\
\text { combined with p1637-63 peptide } \\
\text { and Montanide ISA-5I adjuvant }\end{array}$ & 1/ Completed & $\begin{array}{l}\text { NCT02526316: } 10 \\
\text { patients; single group; } \\
\text { open label }\end{array}$ & No results posted & [24I] \\
\hline \multirow[t]{5}{*}{ ISA I0I } & $\begin{array}{l}9 \text { overlapping long E6 peptides } \\
\text { and } 4 \text { overlapping E7 peptides } \\
\text { from HPV-16 (HPVI6-SLP) with } \\
\text { Montanide ISA } 5 \text { I adjuvant }\end{array}$ & 1/ Completed & $\begin{array}{l}35 \text { patients; } 3 \text { groups } \\
\text { with different doses }\end{array}$ & $\begin{array}{l}\text { Minimal toxicity and } \\
\text { sustained immunogenicity }\end{array}$ & [225] \\
\hline & $\begin{array}{l}\text { HPVI6-SLP with Montanide ISA } \\
5 \text { I adjuvant }\end{array}$ & II/ Completed & $\begin{array}{l}20 \text { patients; single } \\
\text { group }\end{array}$ & $\begin{array}{l}12 \text { patients showed clinical } \\
\text { CTL responses. }\end{array}$ & [226] \\
\hline & $\begin{array}{l}\text { HPVI6-SLP with Montanide ISA } \\
5 \text { I adjuvant }\end{array}$ & II/ Completed & 34 patients & $\begin{array}{l}\text { All patients showed } \\
\text { significant HPV-specific } \\
\text { CTL response. }\end{array}$ & [227] \\
\hline & $\begin{array}{l}\text { HPVI6-SLP, Montanide ISA } 5 \text { I } \\
\text { adjuvant, combined therapy with } \\
\text { nivolumab (PD-I inhibitor) }\end{array}$ & II/ Completed & $\begin{array}{l}\text { NCT02426892: } 24 \\
\text { patients; single-arm; } \\
\text { single-center }\end{array}$ & $\begin{array}{l}\text { No toxicity accumulation; } \\
\text { well-tolerated }\end{array}$ & {$[245]$} \\
\hline & $\begin{array}{l}\text { HPV-SLP, Montanide ISA 5I } \\
\text { adjuvant, CarboTaxol with/ } \\
\text { without Bevacizumab (pegylated } \\
\text { IFN } \alpha \text { as immune modulator) }\end{array}$ & I-II/ Completed & $\begin{array}{l}\text { NCT02।28|26: } 93 \\
\text { participants; } \\
\text { multicenter; open } \\
\text { label }\end{array}$ & No results posted & [242] \\
\hline
\end{tabular}

(Continued) 
Table 4 (Continued).

\begin{tabular}{|c|c|c|c|c|c|}
\hline Vaccine & $\begin{array}{l}\text { Vaccine Composition \& } \\
\text { Adjuvant }\end{array}$ & Phase/ Status & Clinical Trials & Outcomes & Ref \\
\hline \multirow[t]{3}{*}{ PepCan } & \multirow[t]{3}{*}{$\begin{array}{l}\text { Peptides from HPV-16 E6 with } \\
\text { Candin/ Candin as active } \\
\text { comparator }\end{array}$} & I/ Completed & $\begin{array}{l}\text { NCT0056923I: } 24 \\
\text { patients; dose- } \\
\text { escalation }\end{array}$ & No dose-limited toxicity & [236] \\
\hline & & II/ Recruitment & $\begin{array}{l}\text { NCT0248I4I4: } 125 \\
\text { participants; } \\
\text { randomized, doubled- } \\
\text { blinded to two } \\
\text { therapy arms }\end{array}$ & No results posted & [236] \\
\hline & & II/ Recruitment & NCT0382 I 272 & No results posted & [236] \\
\hline \multirow[t]{2}{*}{ PDSOIOI } & $\begin{array}{l}\text { Peptides from HPV-16 E6 and E7, } \\
\text { and } R \text {-enantiomer of I.2-dioleoyl- } \\
\text { 3-trimethylammonium- propane } \\
\text { chloride (R-DOTAP) }\end{array}$ & I/ Completed & $\begin{array}{l}\text { NCT02065973: } 12 \\
\text { patients; open-label; } \\
\text { sequential- cohort; } \\
\text { escalating dose }\end{array}$ & Safety & [239] \\
\hline & $\begin{array}{l}\text { Cisplatin, liposomal HPV-16 E6/E7 } \\
\text { multipeptide with R-DOTAP and } \\
\text { radiation therapy }\end{array}$ & IIA/ Recruitment & $\begin{array}{l}\text { NCT0458077I: } 35 \\
\text { participants; } \\
\text { interventional; single } \\
\text { group assignment; } \\
\text { open label }\end{array}$ & No results posted & [239] \\
\hline DPX-E7 & $\begin{array}{l}\text { HPV- } 16 \mathrm{E7}_{49-57} \text { and PADRE plus } \\
\text { DepoVax }{ }^{\mathrm{TM}} \text { (DPX) adjuvant }\end{array}$ & $\begin{array}{l}\text { Ib-II/ Active, not } \\
\text { recruiting }\end{array}$ & $\begin{array}{l}\text { NCT02865।35: II } \\
\text { participants; } \\
\text { interventional; single } \\
\text { group assignment; } \\
\text { open label }\end{array}$ & No results posted & {$[96,113]$} \\
\hline
\end{tabular}

Adverse events reported were local swelling in $100 \%$ of patients and fever in $64 \%$ of patients. All patients induced a T-cell response after vaccination.

To investigate the ability of the HPV-16 SLP vaccine to stimulate HPV-16-specific T-cell responses in patients with high HPV-16 cervical lesions, van Steenwijk et al ran a placebo-controlled, randomized, blind clinical phase II study including 34 patients. ${ }^{27,229}$ They additionally examined the effect of a booster vaccination after one year and conducted a two-year follow-up. Flu-like symptoms and reactions at the injection site were typical. All vaccinated patients had a significant HPV-specific IFN-associated T-cell response compared with the placebo group. ${ }^{227}$ Booster vaccination one year later substantially increased the HPV-16-specific Th2 response. It was shown that two low-dose HPV16-SLP injections $(50 \mu \mathrm{g}$ peptide) elicited a robust and persistent HPV16-specific T-cell response that lasted for at least one year. ${ }^{229}$ Moreover, van Poelgeest et al evaluated the toxicity, safety, immunogenicity, and effectiveness of HPV-16 SLP plus Montanide ISA 51 vaccination in a single group of 20 patients with advanced or recurring gynecologic malignancies in phase II clinical study. ${ }^{228}$ No systemic toxic responses above CTCAE class II were detected throughout the study, although some patients had transient influenza-like symptoms. ELISPOT analysis revealed that 11/13 individuals exhibited an immunological response to the vaccination. However, in the 12 individuals examined, no tumor regression was found. Nineteen individuals passed away because of tumor growth. The HPV-16 SLP vaccination was well tolerated and elicited a widespread T-cell response but did not result in tumor remission or disease progression. As a result, ISA101 alone showed promise in cervical intraepithelial neoplasia but had little effect on advanced cervical cancer. The vaccination was utilized in subsequent clinical studies in combination with chemotherapy and immunomodulatory treatment. 
In addition to clinical studies on HPV-specific antigenic epitopes, Hasegawa et al reported on a phase I clinical trial (UMIN000003999) combining five peptides, respectively, derived from forkhead box protein M1 (FOXM1)-262 (IYTWIEDHF), maternal embryonic leucine zipper kinase (MELK)-87-7N (EYCPGGNLF), Holliday junctionrecognition protein (HJURP)-408 (KWLISPVKI), and vascular endothelial growth factor receptors (VEGFR)-1-1084 (SYGVLLWEI) and VEGFR-2-169 (RFVPDGNRI), in nine patients with HLA-A*2402 cervical cancer. ${ }^{230}$ In a doseescalation trial, three doses of each peptide of $0.5,1$, and $2 \mathrm{mg}$ were combined with $0.5,1$, and $2 \mathrm{~mL}$ of Montanide ISA 51 and administered to patients four times. There was no dose-limiting toxicity associated with the vaccinations, and they were well tolerated. In eight (89\%) and seven (78\%) patients, respectively, IFN- $\gamma$ ELISPOT tests revealed significant T-cell responses to FOXM1 and MELK.

Safety and efficacy were examined for GM-CSF and CpG-ODN as immune-stimulating adjuvants in combination with Wilms' Tumor 1 (WT1) vaccine (WT1 peptide emulsified with Montanide ISA 51) for the treatment of patients with solid malignancies in a phase I clinical trial (UMIN000002771). ${ }^{231}$ Wilms' oncogene WT1 is extensively expressed in malignant tumors and has theoretical advantages as a cancer immunotherapy target antigen. ${ }^{232}$ 9-polymer WT1 $187-195$ (SLGEQQYSV) was used to inoculate patients with HLA-A*0201 and A*0206; a modified 9-polymer WT1 $235-243$ (CYTWNQMNL) was used to inoculate patients with HLA-A*2402. ${ }^{231}$ The study included 28 patients with solid malignancies, including cervical cancer. The inclusion of GM-CSF or CpG-ODN to the WT1 peptide vaccination was shown to be safe and enhanced the effectiveness of clinical responses in patients with solid malignancies. Patients treated with the WT1 peptide plus CpG-ODN (60\%) had significantly higher illness control rates than the other groups, indicating that $\mathrm{CpG}$ is a superior immunological adjuvant compared to GM-CSF. Subsequently, a clinical phase II trial was initiated in patients with gynecologic malignancies, including 11/40 cases of cervical cancer, based on a determined safe dose of WT1 peptide ( $3 \mathrm{mg}$ ) emulsified with Montanide ISA 51 adjuvant. ${ }^{233}$ Of these patients, $40 \%$ showed longlasting antitumor effects within three months, but $90 \%$ experienced varying skin toxicity levels, and adverse effects were observed.

The high overexpression of $\mathrm{p} 16^{\mathrm{INK} 4 \mathrm{a}}$, a cellular protein that acts as a hallmark for HPV-associated malignancies, has emerged as a novel vaccination target. P16 $37-63$ and Montanide ISA-51 were administered subcutaneously to 28 patients with HPV-associated neoplasia in the first phase I/IIa human study (NCT01462838). ${ }^{234}$ There was no dose-limiting toxicity, and the vaccination boosted $\mathrm{CD}^{+} \mathrm{T}$ cells in $11 / 20$ patients, $\mathrm{CD} 8^{+} \mathrm{T}$ cells in $4 / 20$ patients, and antibody production in $14 / 20$ patients.

PepCan is a therapeutic peptide-based vaccine against HPV that consists of four peptides $\left(\mathrm{E}_{1-45}, \mathrm{E} 6_{46-80}, \mathrm{E} 6_{81-115}\right.$, and E6 $6_{116-158}$ ) covering HPV-16 E6 and a novel adjuvant Candin, which is a colorless extract of Candida albicans. ${ }^{235,236}$ Candin has been shown in vitro to stimulate T-cell proliferation and IL-12 secretion by Langerhans cells, the primary antigen-presenting cells in the skin. ${ }^{237}$ Twenty-four female patients with cervical intraepithelial neoplasia $2 / 3$ received a total of four intradermal injections at 3-week intervals in a dose-escalating clinical phase I study (NCT00569231). ${ }^{238}$ Each peptide was dosed incrementally at 50,100, 250, and $500 \mu \mathrm{g}$, with $50 \mu \mathrm{g}$ demonstrating the highest rate of histological regression ( $50 \%$ complete regression) and the most substantial virological response ( $85 \%$ viral clearance). In addition, no dose-limiting toxicity was observed in the 10 patients administered with $50 \mu \mathrm{g}$ of vaccine. ${ }^{236}$ After confirming the safety of PepCan, recruitment for phase II clinical studies (NCT03821272 and NCT02481414) was initiated for cytokine/chemokine and proteome research to evaluate the feasibility of possible biomarkers. ${ }^{236}$ Similarly, another clinical phase I dose-escalation trial (NCT01653249) consisted of four identical HPV-16 E6 peptides combined with Candin in 52 women. The vaccine was designed to cure a precancerous lesion, called high-grade squamous intraepithelial neoplasia (HSIL). ${ }^{235}$ In this formulation, the peptide was key to inducing the maturation effect of Langerhans cells, thereby inducing the cytokine IL-12. Candin was responsible for the proliferative effect of T cells.

The liposomal-based HPV therapeutic vaccine, PDS0101, consisted of six peptide antigens from HPV-16 E6 and E7 and $R$-DOTAP, the immunologically superior $R$-enantiomer of the cationic lipid 1.2-dioleoyl-3-trimethylammoniumpropane. ${ }^{204}$ The vaccine showed safety in a phase I clinical trial (NCT02065973), and it fulfilled the secondary endpoints of cervical dysplasia regression and increased antigen-specific $\mathrm{CD} 4^{+}$and $\mathrm{CD} 8^{+} \mathrm{T}$ cells (no detailed report available). ${ }^{239}$

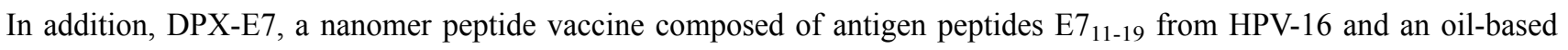
delivery system, DepoVax ${ }^{\mathrm{TM}}$ (DPX), suspended the antigen peptides in the oil phase, forcing immune cells to absorb and 
bind to antigens without direct passive release. ${ }^{96,240} \mathrm{~A}$ phase Ib-II trial (NCT02865135) is active, but has not yet completed recruitment to examine the safety and efficacy of HPV16-E7 $7_{11-19}$ nanomonomer vaccination for the treatment of incurable HPV 16-associated oropharyngeal, cervical, and anal cancers in HLA-A*02-positive patients. ${ }^{96,113}$

\section{Combination Therapy in Clinical Trials}

The combination of immunotherapeutic methods represents a challenging strategy to enhance antitumor immunity by targeting several immune response components, such as chemotherapy, radiotherapy, immune checkpoint inhibitors, and biological agents. Many preclinical studies have proven the effectiveness of combination therapy approaches with peptide-based vaccines for cervical cancer. However, no vaccine has entered phase III clinical trials or demonstrated substantial improvements in overall survival randomly. For example, cisplatin-based or carboplatin-based chemotherapy, P16 $37-63(100 \mu \mathrm{g})$ mixed with Montanide ISA 51, was administered subcutaneously to 10 patients with HPV-associated anogenital cancer (including cervical cancer) and HPV-associated head and neck cancer in a phase I trial (NCT02526316). ${ }^{241}$ Unfortunately, no results have been made publicly available to date. Moreover, a phase IIA clinical trial (NCT04580771) was initiated to investigate the effects of the liposome vaccine PDS0101 given in combination with chemotherapy (Cisplatin) and radiotherapy for the treatment of patients with stage IB3-IVA cervical cancer; the results have not yet been published.

Furthermore, combining CarboTaxol (carboplatin and paclitaxel), ISA 101, and intravaginal TLR9 agonist CpG as tritherapy has undergone a clinical phase I-II trial (NCT02128126), with results pending. ${ }^{242}$ CarboTaxol is a commonly used chemotherapeutic agent that is recommended for the treatment of a variety of cancers, including cervical cancer. Although it promotes DC-mediated antigen presentation, both carboplatin and paclitaxel have the potential to induce dose-limiting myeloid toxicity. ${ }^{243}$ Welters et al reported a clinical study on a group of six patients who received CarboTaxol chemotherapy versus another group of 12 patients treated with CarboTaxol and ISA 101 (300 $\mu \mathrm{g}$ peptide). ${ }^{243}$ Patients treated with CarboTaxol demonstrated a reduction in myeloid cells and an increase in lymphocytes 1-2 weeks after the second dose of chemotherapy. T-cell function improved even though the number of $\mathrm{CD} 4^{+}$and $\mathrm{CD} 8^{+}$ $\mathrm{T}$ cells did not change. After vaccination with ISA 101, 11/12 patients induced a proliferative T-cell response. Vaccination was well tolerated, and most adverse reactions were confined to the injection site.

Another seemingly obvious strategy is to combine vaccinations with immune checkpoint inhibitors, which promote specific $\mathrm{T}$ cell responses by reversing immunosuppression. Immune checkpoints usually use antibodies to block negative regulatory receptors on T cells to stimulate a CTL response to cancerous cells. Inhibitors of programmed death protein 1/ programmed death ligand 1 (PD-1/PD-L1) represent a potentially beneficial therapeutic strategy. Pembrolizumab and nivolumab were approved as immune checkpoint inhibitors by the FDA to treat advanced PD-L1-positive cervical cancer that progressed during or after chemotherapy. The combination of vaccines and immune checkpoints has been proven to increase the immune efficacy of vaccines significantly. ${ }^{244}$

Twenty-four patients with incurable HPV-associated cancer were recruited for a single-arm nonrandomized phase II clinical trial. They were treated by a combination of PD-1 inhibitor nivolumab and ISA 101 (100 $\mu$ g peptide) ${ }^{245}$ Eight of the 24 patients achieved responses, including two complete and six partial responses, resulting in a $33 \%$ overall response rate. The median response duration was 10.3 months, and the median overall survival was 17.5 months. The combination of ISA 101 with nivolumab was well tolerated, with no synergistic toxicity accumulation and only substantial cumulative effects of each agent compared to nivolumab monotherapy. However, broader randomized trials are necessary to demonstrate the efficacy of vaccination in conjunction with PD-1 checkpoint inhibition.

A combined immunotherapy phase II clinical trial (NCT04260126) with PDS0101, in combination with pembrolizumab, has been initiated and is expected to recruit 95 patients for the treatment of HPV16 and PD-L1 positive recurrent or metastatic head and neck squamous cell carcinoma (HNSCC). Interestingly, another clinical phase I-II trial (NCT04287868) is recruiting 56 patients to evaluate the safety of the combination of PDS0101, NHS-interleukin-12 (NHS-IL12), and M7824 in patients with advanced or metastatic HPV-associated malignancies. ${ }^{239}$ NHS-IL12 is an immune cytokine that targets tumors by introducing IL-12 into the tumor microenvironment to enhance the inflammatory Th1 response. M7824, also known as bintrafusp alfa, is a novel bifunctional fusion protein. It is a monoclonal antibody to the extracellular structural domain of transforming growth factor- $\beta$ receptor type II (TGF $\beta$ RII) fused to human IgG 1 to 
block programmed cell death protein-1 ligand (PDL1). As such, it acts both as a checkpoint inhibitor and to introduce TGFßRII into the tumor microenvironment. In preclinical trials, combining the three compounds promoted superior induction of immunoreactive tumor infiltration, and HPV-specific $\mathrm{CD}^{+}$and $\mathrm{CD}^{+} \mathrm{T}$ cells for maximal antitumor effects. $^{239}$

\section{Conclusion}

Therapeutic HPV vaccines are urgently needed to lower the burden of cervical cancer. While effective, prophylactic HPV vaccines cannot help patients who have already been infected with HPV and are growing tumors due to their infection. Unlike with preventative HPV vaccines, progress in the development of therapeutics has been slow due to the lack of clear association between generated immune responses and clinical outcomes in vaccinated individuals. This has been attributed to incomplete understanding of the immune response mechanisms that govern and eliminate cervical cancer in humans. Moreover, the cancer microenvironment and immune evasion pathways are still unclear.

Peptide-based vaccines offer an effective vaccine delivery platform capable of producing efficient immune responses for the treatment of HPV infection. However, peptide-based vaccines suffer from low immunogenicity associated with the small antigenic peptides. Fortunately, these vaccines can be enhanced by the addition of adjuvants and/or delivery systems.

Several predominant adjuvants, including emulsion (water-in-oil/oil-in-water), polymeric nanoparticles, liposome nanoparticles, virus-like particles, granulocyte-macrophage colony-stimulating factor, bacterial flagellin, and synthetic ODN-CpG, have been developed to enhance immunogenicity against cervical cancer. Still, additional non-toxic adjuvants that offer high biocompatibility, immunostimulatory efficiency, and biodegradability are needed for utilization in cervical cancer vaccines.

To date, no therapeutic HPV peptide-based vaccines have entered phase III clinical trials. However, based on comparative preclinical and clinical data, combination immunotherapy may pave the way for this achievement. Combined immunotherapy has been shown to stimulate specific immune responses to tumor-associated antigens by modulating the tumor microenvironment while producing local immunosuppression. For example, combination immunotherapy of HPV16-SLP-based vaccine adjuvanted with Montanide ISA 51 and the PD-1 immune checkpoint inhibitor, nivolumab, was able to avoid the immunosuppression effect developed by the tumor microenvironment.

The following key challenges in vaccine design should be investigated in more detail: (1) in-depth study of antigenic epitopes and the use of multiple epitopes in combination; (2) the selection of adjuvants and the development of selfassembled adjuvant materials to construct a vaccine delivery system; and (3) the combination of peptide-based vaccines with other forms of immunotherapy.

Overall, the development of peptide-based vaccines has a promising future in combating HPV infection and cervical cancer. We anticipate that advanced knowledge of the immunological mechanisms of HPV infection, and novel approaches for developing better vaccines and superior adjuvants will lead to more effective vaccines in the future.

\section{Acknowledgments}

This work was supported by the National Health and Medical Research Council (NHMRC Program Grant APP1132975).

\section{Disclosure}

The authors report no conflicts of interest in this work.

\section{References}

1. Crosbie EJ, Einstein MH, Franceschi S, Kitchener HC. Human papillomavirus and cervical cancer. Lancet. 2013;382(9895):889-899. doi:10.1016/ S0140-6736(13)60022-7

2. Walboomers JMM, Jacobs MV, Manos MM, et al. Human papillomavirus is a necessary cause of invasive cervical cancer worldwide. $J$ Pathol. 1999;189(1):12-19.

3. Pal A, Kundu R. Human papillomavirus E6 and E7: the cervical cancer hallmarks and targets for therapy. Front Microbiol. 2019;10:3116.

4. Prat J. Pathology of cancers of the female genital tract. Int J Gynecol Obstet. 2015;131:S132-S145. 
5. Cervical cancer treatment. Cellular classification of cervical cancer; 2020. Available from: https://www.cancer.gov/types/cervical/hp/cervicaltreatment-pdq\#link/_405_toc. Accessed September 3, 2020.

6. Zepp F. Principles of vaccine design-Lessons from nature. Vaccine. 2010;28(Suppl 3):C14-24.

7. Toussaint B, Chauchet X, Wang Y, Polack B, Le Gouellec A. Live-attenuated bacteria as a cancer vaccine vector. Expert Rev Vaccines. 2013;12 (10):1139-1154.

8. Kelly HG, Kent SJ, Wheatley AK. Immunological basis for enhanced immunity of nanoparticle vaccines. Expert Rev Vaccines. 2019;18 (3):269-280.

9. Castle PE, Maza M. Prophylactic HPV vaccination: past, present, and future. Epidemiol Infect. 2016;144(3):449-468.

10. Hancock G, Hellner K, Dorrell L. Therapeutic HPV vaccines. Best Pract Res Clin Obstet Gynaecol. 2018;47:59-72. doi:10.1016/j. bpobgyn.2017.09.008

11. Hung C-F, Ma B, Monie A, Tsen S-W, Wu T-C. Therapeutic human papillomavirus vaccines: current clinical trials and future directions. Expert Opin Biol Ther. 2008;8(4):421-439. doi:10.1517/14712598.8.4.421

12. Wang R, Pan W, Jin L, et al. Human papillomavirus vaccine against cervical cancer: opportunity and challenge. Cancer Lett. 2020;471:88-102. doi:10.1016/j.canlet.2019.11.039

13. Liu T-Y, Hussein WM, Toth I, Skwarczynski M. Advances in peptide-based human papillomavirus therapeutic vaccines. Curr Top Med Chem. 2012;12(14):1581-1592. doi:10.2174/156802612802652402

14. Paston SJ, Brentville VA, Symonds P, Durrant LG. Cancer vaccines, adjuvants, and delivery systems. Front Immunol. 2021;12:627932. doi:10.3389/fimmu.2021.627932

15. Skwarczynski M, Toth I. Peptide-based synthetic vaccines. Chem Sci. 2016;7(2):842-854. doi:10.1039/C5SC03892H

16. Azuar A, Jin J, Mukaida M, et al. Recent advances in the development of peptide vaccines and their delivery systems against group A Streptococcus. Vaccines. 2019;7(3):58. doi:10.3390/vaccines7030058

17. Skwarczynski M, Toth I. Recent advances in peptide-based subunit nanovaccines. Nanomedicine. 2014;9(17):2657-2669.

18. Al-Halifa S, Gauthier L, Arpin D, Bourgault S, Archambault D. Nanoparticle-based vaccines against respiratory viruses. Front Immunol. 2019;10:22.

19. Deivendran S, Marzook KH, Radhakrishna pillai M. The role of inflammation in cervical cancer. Adv Exp Med Biol. 2014;816:377-399.

20. Arbyn M, Weiderpass E, Bruni L, et al. Estimates of incidence and mortality of cervical cancer in 2018: a worldwide analysis. Lancet Glob Health. 2020;8(2):e191-e203.

21. Bray F, Ferlay J, Soerjomataram I, et al. Global cancer statistics 2018: GLOBOCAN estimates of incidence and mortality worldwide for 36 cancers in 185 countries. CA Cancer J Clin. 2018;68(6):394-424.

22. Buskwofie A, David-West G, Clare CA. A review of cervical cancer: incidence and disparities. J Natl Med Assoc. 2020;112(2):229-232.

23. Mboumba Bouassa RS, Prazuck T, Lethu T, et al. Cervical cancer in sub-Saharan Africa: a preventable noncommunicable disease. Expert Rev Anti Infect Ther. 2017;15(6):613-627.

24. Canfell K, Kim JJ, Brisson M, et al. Mortality impact of achieving WHO cervical cancer elimination targets: a comparative modelling analysis in 78 low-income and lower-middle-income countries. Lancet. 2020;395(10224):591-603.

25. Small W Jr., Bacon MA, Bajaj A, et al. Cervical cancer: a global health crisis. Cancer. 2017;123(13):2404-2412.

26. Sadri NJ, Moghoofei M, Salmaninejad A, et al. Pathogenic role of exosomes and microRNAs in HPV-mediated inflammation and cervical cancer: a review. Int $J$ Cancer. 2019;146(2):305-320.

27. Shrestha AD, Neupane D, Vedsted P, Kallestrup P. Cervical cancer prevalence, incidence and mortality in low and middle income countries: a systematic review. Asian Pac J Cancer Prev. 2018;19(2):319-324.

28. Smith RA, Andrews KS, Brooks D, et al. Cancer screening in the United States, 2018: a review of current American Cancer Society guidelines and current issues in cancer screening. CA Cancer J Clin. 2018;68(4):297-316.

29. Yim EK, Park JS. The role of HPV E6 and E7 oncoproteins in HPV-associated cervical carcinogenesis. Cancer Res Treat. 2005;37(6):319-324.

30. Arbyn M, Castellsague X, de Sanjose S, et al. Worldwide burden of cervical cancer in 2008. Ann Oncol. 2011;22(12):2675-2686.

31. Kiatpongsan S, Kim JJ. Costs and cost-effectiveness of 9-valent human papillomavirus (HPV) vaccination in two East African countries. PLoS One. 2014;9(9):e106836.

32. Fang J, Zhang H, Jin S. Epigenetics and cervical cancer: from pathogenesis to therapy. Tumour Biol. 2014;35(6):5083-5093.

33. Yang A, Jeang J, Cheng K, et al. Current state in the development of candidate therapeutic HPV vaccines. Expert Rev Vaccines. 2016;15 (8):989-1007.

34. Ngoma M, Autier P. Cancer prevention: cervical cancer. Ecancermedicalscience. 2019;13:952.

35. World Health Organization. Human papillomavirus vaccines: WHO position paper, May 2017-Recommendations. Vaccine. 2017;35 (43):5753-5755.

36. Harper DM, DeMars LR. HPV vaccines - a review of the first decade. Gynecol Oncol. 2017;146(1):196-204.

37. Pinto LA, Edwards J, Castle PE, et al. Cellular immune responses to human papillomavirus (HPV)-16 L1 in healthy volunteers immunized with recombinant HPV-16 L1 virus-like particles. J Infect Dis. 2003;188(2):327-338.

38. Harro CD, Pang YY, Roden RB, et al. Safety and immunogenicity trial in adult volunteers of a human papillomavirus $16 \mathrm{~L} 1$ virus-like particle vaccine. J Natl Cancer Inst. 2001;93(4):284-292.

39. Ghittoni R, Accardi R, Chiocca S, Tommasino M. Role of human papillomaviruses in carcinogenesis. Ecancermedicalscience. $2015 ; 9: 526$.

40. Zhai L, Tumban E. Gardasil-9: a global survey of projected efficacy. Antiviral Res. 2016;130:101-109.

41. Luckett R, Feldman S. Impact of 2-, 4- and 9-valent HPV vaccines on morbidity and mortality from cervical cancer. Hum Vaccin Immunother. 2016;12(6):1332-1342.

42. Poljak M. Prophylactic human papillomavirus vaccination and primary prevention of cervical cancer: issues and challenges. Clin Microbiol Infect. 2012;18(Suppl 5):64-69.

43. Madrid-Marina V, Torres-Poveda K, Lopez-Toledo G, Garcia-Carranca A. Advantages and disadvantages of current prophylactic vaccines against HPV. Arch Med Res. 2009;40(6):471-477.

44. Burk RD, Harari A, Chen Z. Human papillomavirus genome variants. Virology. 2013;445(1):232-243. 
45. Hu Z, Ma D. The precision prevention and therapy of HPV-related cervical cancer: new concepts and clinical implications. Cancer Med. 2018; 7 (10):5217-5236.

46. Harden ME, Munger K. Human papillomavirus molecular biology. Mutat Res Rev Mutat Res. 2017;772:3-12.

47. Zur Hausen H. Papillomaviruses in the causation of human cancers - a brief historical account. Virology. 2009;384(2):260-265.

48. Doorbar J, Quint W, Banks L, et al. The biology and life-cycle of human papillomaviruses. Vaccine. 2012;30(Suppl 5):F55-70.

49. Panczyszyn A, Boniewska-Bernacka E, Glab G. Telomeres and telomerase during human papillomavirus-induced carcinogenesis. Mol Diagn Ther. 2018;22(4):421-430.

50. Muñoz N, Bosch FX, de Sanjosé S, et al. Epidemiologic classification of human papillomavirus types associated with cervical cancer. $N$ Engl J Med. 2003;348(6):518-527.

51. Stanley M. Pathology and epidemiology of HPV infection in females. Gynecol Oncol. 2010;117(2 Supplement):S5-S10.

52. Graham Sheila V. The human papillomavirus replication cycle, and its links to cancer progression: a comprehensive review. Clin Sci. 2017;131 (17):2201-2221.

53. Burd EM. Human papillomavirus and cervical cancer. Clin Microbiol Rev. 2003;16(1):1-17.

54. Chang YE, Laimins LA. Microarray analysis identifies interferon-inducible genes and Stat-1 as major transcriptional targets of human papillomavirus type 31. J Virol. 2000;74(9):4174-4182.

55. Egawa N, Doorbar J. The low-risk papillomaviruses. Virus Res. 2017;231:119-127.

56. Doorbar J, Egawa N, Griffin H, Kranjec C, Murakami I. Human papillomavirus molecular biology and disease association. Rev Med Virol. 2015;25(Suppl 1):2-23.

57. Zheng ZM, Baker CC. Papillomavirus genome structure, expression, and post-transcriptional regulation. Front Biosci. $2006 ; 11: 2286-2302$.

58. Prati B, Marangoni B, Boccardo E. Human papillomavirus and genome instability: from productive infection to cancer. Clinics. 2018; 73:e539s.

59. Yeo-Teh NSL, Ito Y, Jha S. High-risk human papillomaviral oncogenes E6 and E7 target key cellular pathways to achieve oncogenesis. Int J Mol Sci. 2018;19(6):1706.

60. Graham SV. Human papillomavirus: gene expression, regulation and prospects for novel diagnostic methods and antiviral therapies. Future Microbiol. 2010;5(10):1493-1506

61. Xue J, Vesper BJ, Radosevich JA. Proteins encoded by the human papillomavirus genome and their functions. In: Radosevich JA, editor. HPV and Cancer. Dordrecht: Springer; 2012.

62. Finnen RL, Erickson KD, Chen XS, Garcea RL. Interactions between papillomavirus L1 and L2 capsid proteins. J Virol. 2003;77 (8):4818-4826.

63. Wang JW, Roden RB. L2, the minor capsid protein of papillomavirus. Virology. 2013;445(1-2):175-186.

64. Ibeanu OA. Molecular pathogenesis of cervical cancer. Cancer Biol Ther. 2011;11(3):295-306.

65. Doorbar J. The E4 protein; structure, function and patterns of expression. Virology. 2013;445(1-2):80-98.

66. Venuti A, Paolini F, Nasir L, et al. Papillomavirus E5: the smallest oncoprotein with many functions. Mol Cancer. 2011;10:140.

67. Hwang ES, Nottoli T, Dimaio D. The HPV16 E5 protein: expression, detection, and stable complex formation with transmembrane proteins in COS cells. Virology. 1995;211(1):227-233.

68. Hoppe-Seyler K, Bossler F, Braun JA, Herrmann AL, Hoppe-Seyler F. The HPV E6/E7 oncogenes: key factors for viral carcinogenesis and therapeutic targets. Trends Microbiol. 2018;26(2):158-168.

69. Thomas M, Pim D, Banks L. The role of the E6-p53 interaction in the molecular pathogenesis of HPV. Oncogene. 1999;18(53):7690-7700.

70. Martinez-Zapien D, Ruiz FX, Poirson J, et al. Structure of the E6/E6AP/p53 complex required for HPV-mediated degradation of p53. Nature. 2016;529(7587):541-545.

71. Nomine Y, Masson M, Charbonnier S, et al. Structural and functional analysis of E6 oncoprotein: insights in the molecular pathways of human papillomavirus-mediated pathogenesis. Mol Cell. 2006;21(5):665-678.

72. Kuss-Duerkop SK, Westrich JA, Pyeon D. DNA tumor virus regulation of host DNA methylation and its implications for immune evasion and oncogenesis. Viruses. 2018;10(2):82.

73. Barbosa MS, Edmonds C, Fisher C, et al. The region of the HPV E7 oncoprotein homologous to adenovirus E1a and Sv40 large T antigen contains separate domains for Rb binding and casein kinase II phosphorylation. EMBO J. 1990;9(1):153-160.

74. Boulet G, Horvath C, Vanden Broeck D, Sahebali S, Bogers J. Human papillomavirus: E6 and E7 oncogenes. Int J Biochem Cell Biol. 2007;39 (11):2006-2011.

75. Roman A, Munger K. The papillomavirus E7 proteins. Virology. 2013;445(1-2):138-168.

76. Phelps WC, Yee CL, Munger K, Howley PM. The human papillomavirus type 16 E7 gene encodes transactivation and transformation functions similar to those of adenovirus E1A. Cell. 1988;53(4):539-547.

77. Liu X, Clements A, Zhao K, Marmorstein R. Structure of the human papillomavirus E7 oncoprotein and its mechanism for inactivation of the retinoblastoma tumor suppressor. J Biol Chem. 2006;281(1):578-586.

78. Corteggio A, Altamura G, Roperto F, Borzacchiello G. Bovine papillomavirus E5 and E7 oncoproteins in naturally occurring tumors: are two better than one? Infect Agents Cancer. 2013;8(1):1.

79. Giarre M, Caldeira S, Malanchi I, et al. Induction of pRb degradation by the human papillomavirus type 16 E7 protein is essential to efficiently overcome p16INK4a-imposed G1 cell cycle Arrest. J Virol. 2001;75(10):4705-4712.

80. Albert E, Laimins L. Regulation of the human papillomavirus life cycle by DNA damage repair pathways and epigenetic factors. Viruses. 2020;12(7).

81. Mac M, Moody CA. Epigenetic regulation of the human papillomavirus life cycle. Pathogens. 2020;9(6):744.

82. Burley M, Roberts S, Parish JL. Epigenetic regulation of human papillomavirus transcription in the productive virus life cycle. Semin Immunopathol. 2020;42(2):159-171.

83. Stubenrauch F, Laimins LA. Human papillomavirus life cycle: active and latent phases. Semin Cancer Biol. 1999;9(6):379-386.

84. Netea MG, Schlitzer A, Placek K, Joosten LAB, Schultze JL. Innate and adaptive immune memory: an evolutionary continuum in the host's response to pathogens. Cell Host Microbe. 2019;25(1):13-26.

85. Arango DG, Descoteaux A. Macrophage cytokines: involvement in immunity and infectious diseases. Front Immunol. 2014;5:491.

86. McComb S, Thiriot A, Akache B, Krishnan L, Stark F. Introduction to the Immune System. Methods Mol Biol. 2019;2024:1-24. 
87. Purcell AW, McCluskey J, Rossjohn J. More than one reason to rethink the use of peptides in vaccine design. Nat Rev Drug Discov. 2007;6 (5):404-414.

88. de Souza AP, Bonorino C. Tumor immunosuppressive environment: effects on tumor-specific and nontumor antigen immune responses. Expert Rev Anticancer Ther. 2009;9(9):1317-1332.

89. Gubin MM, Ward JP, Noguchi T, et al. Tumor-specific mutant antigens in cancer immunotherapy. Cancer Immunol Res. 2016;4(11). doi:10.1158/2326-6066.IMM2016-A001

90. Gubin MM, Zhang XL, Schuster H, et al. Checkpoint blockade cancer immunotherapy targets tumour-specific mutant antigens. Nature. 2014;515(7528):577.

91. Fang S, Lisiero D, Liau L, Prins R. Epigenetic regulation of tumor-associated antigens enhances immunotherapy by sensitizing murine glioma cells to cell death by tumor-specific CD8+T cells. Neuro-Oncology. 2008;10(5):811.

92. Hui KM, Kim BS. Tumor-specific immunity induced by somatic hybrids.4. relationship between immunogenicity and expression of surface tumor-associated antigens. Cell Immunol. 1984;87(2):591-600.

93. Wagner S, Mullins CS, Linnebacher M. Colorectal cancer vaccines: tumor-associated antigens vs neoantigens. World J Gastroenterol. 2018;24 (48):5418-5432.

94. Stark JM, Tibbitt CA, Coquet JM. The metabolic requirements of Th2 cell differentiation. Front Immunol. 2019;10:2318.

95. Lin C-N, Chien C-Y, Chung H-C. Are friends or foes? New strategy for head and neck squamous cell carcinoma treatment via Immune regulation. Int J Head Neck Sci. 2017;1(2):105-113.

96. Yang A, Farmer E, Wu TC, Hung CF. Perspectives for therapeutic HPV vaccine development. J Biomed Sci. 2016;23(1):75.

97. van der Burg SH, Arens R, Ossendorp F, van Hall T, Melief CJM. Vaccines for established cancer: overcoming the challenges posed by immune evasion. Nat Rev Cancer. 2016;16(4):219-233.

98. Malonis RJ, Lai JR, Vergnolle O. Peptide-based vaccines: current progress and future challenges. Chem Rev. 2020;120(6):3210-3229.

99. Gatti-Mays ME, Redman JM, Collins JM, Bilusic M. Cancer vaccines: enhanced immunogenic modulation through therapeutic combinations. Hum Vaccin Immunother. 2017;13(11):2561-2574. doi:10.1080/21645515.2017.1364322

100. Vici P, Pizzuti L, Mariani L, et al. Targeting immune response with therapeutic vaccines in premalignant lesions and cervical cancer: hope or reality from clinical studies. Expert Rev Vaccines. 2016;15(10):1327-1336. doi:10.1080/14760584.2016.1176533

101. Skwarczynski M, Toth I. Peptide-based subunit nanovaccines. Curr Drug Deliv. 2011;8(3):282-289. doi:10.2174/156720111795256192

102. Hussein WM, Skwarczynski M, Istvan T. An isodipeptide building block for microwave-assisted solid-phase synthesis of difficult sequence-containing peptides. Methods Mol Biol. 2020;2103:139-150.

103. Hussein WM, Liu T-Y, Toth I, Skwarczynski M. Microwave-assisted synthesis of difficult sequence-containing peptides using the isopeptide method. Org Biomol Chem. 2013;11(14):2370-2376. doi:10.1039/c3ob00030c

104. Andreatta M, Nielsen M. Bioinformatics tools for the prediction of T-cell epitopes. Methods Mol Biol. 2018;1785:269-281.

105. Sharma G, Rive CM, Holt RA. Rapid selection and identification of functional CD8+ T cell epitopes from large peptide-coding libraries. Nat Commun. 2019;10(1):4553. doi:10.1038/s41467-019-12444-7

106. Wieczorek M, Abualrous ET, Sticht J, et al. Major histocompatibility complex (MHC) class I and MHC class II proteins: conformational plasticity in antigen presentation. Front Immunol. 2017;8. doi:10.3389/fimmu.2017.00292

107. Kaliamurthi S, Selvaraj G, Junaid M, et al. Cancer immunoinformatics: a promising era in the development of peptide vaccines for human papillomavirus-induced cervical cancer. Curr Pharm Des. 2019;24(32):3791-3817. doi:10.2174/1381612824666181106094133

108. Liao WWP, Arthur JW. Predicting peptide binding to major histocompatibility complex molecules. Autoimmun Rev. 2011;10(8):469-473. doi:10.1016/j.autrev.2011.02.003

109. Liu W, Tang H, Li L, et al. Peptide-based therapeutic cancer vaccine: current trends in clinical application. Cell Prolif. 2021;54(5):e13025e13025. doi:10.1111/cpr.13025

110. Lundegaard C, Hoof I, Lund O, Nielsen M. State of the art and challenges in sequence based T-cell epitope prediction. Immunome Res. 2010;6 (2):S3. doi:10.1186/1745-7580-6-S2-S3

111. Kaliamurthi S, Selvaraj G, Kaushik AC, Gu K-R, Wei D-Q. Designing of CD8(+) and CD8(+)-overlapped CD4(+) epitope vaccine by targeting late and early proteins of human papillomavirus. Biol Targets Ther. 2018;12:107-125.

112. Kaliamurthi S, Selvaraj G, Chinnasamy S, et al. Exploring the papillomaviral proteome to identify potential candidates for a chimeric vaccine against cervix papilloma using immunomics and computational structural vaccinology. Viruses. 2019;11(1):63. doi:10.3390/v11010063

113. Ma W, Melief CJM, van der Burg SH. van der Burg SH. Control of immune escaped human papilloma virus is regained after therapeutic vaccination. Curr Opin Virol. 2017;23:16-22. doi:10.1016/j.coviro.2017.02.005

114. Zhao Y, Wang H, Yang Y, et al. Mannose-modified liposome co-delivery of human papillomavirus type 16 E7 peptide and CpG oligodeoxynucleotide adjuvant enhances antitumor activity against established large TC-1 grafted tumors in mice. Int $J$ Nanomedicine. 2020;15:9571-9586. doi:10.2147/IJN.S275670

115. Liu T-Y, Hussein WM, Jia Z, et al. Self-adjuvanting polymer-peptide conjugates as therapeutic vaccine candidates against cervical cancer. Biomacromolecules. 2013;14(8):2798-2806. doi:10.1021/bm400626w

116. Tindle RW, Fernando GJ, Sterling JC, Frazer IH. A "public" T-helper epitope of the E7 transforming protein of human papillomavirus 16 provides cognate help for several E7 B-cell epitopes from cervical cancer-associated human papillomavirus genotypes. PNAS. 1991;88 (13):5887-5891. doi:10.1073/pnas.88.13.5887

117. Bahmani B, Amini-bayat Z, Ranjbar MM, Bakhtiari N, Zarnani A-H. HPV16-E7 protein T cell epitope prediction and global therapeutic peptide vaccine design based on human leukocyte antigen frequency: an in-silico study. Int J Pept Res Ther. 2021;27(1):365-378. doi:10.1007/s10989020-10089-5

118. de Oliveira LMF, Morale MG, Chaves AAM, et al. Design, immune responses and anti-tumor potential of an HPV16 E6E7 multi-epitope vaccine. PLoS One. 2015;10(9):e0138686-e0138686. doi:10.1371/journal.pone.0138686

119. Cordeiro MN, De Lima RDCP, Paolini F, et al. Current research into novel therapeutic vaccines against cervical cancer. Expert Review of Anticancer Therapy. 2018;18(4):365-376. doi:10.1080/14737140.2018.1445527 
120. Morishima S, Akatsuka Y, Nawa A, et al. Identification of an HLA-A24-restricted cytotoxic T lymphocyte epitope from human papillomavirus type-16 E6: the combined effects of bortezomib and interferon- $\gamma$ on the presentation of a cryptic epitope. Int J Cancer. $2007 ; 120(3): 594-604$. doi:10.1002/ijc. 22312

121. Hussein WM, Liu T-Y, Jia Z, et al. Multiantigenic peptide-polymer conjugates as therapeutic vaccines against cervical cancer. Bioorg Med Chem. 2016;24(18):4372-4380. doi:10.1016/j.bmc.2016.07.036

122. Manuri PR, Nehete B, Nehete PN, et al. Intranasal immunization with synthetic peptides corresponding to the E6 and E7 oncoproteins of human papillomavirus type 16 induces systemic and mucosal cellular immune responses and tumor protection. Vaccine. 2007;25(17):3302-3310. doi:10.1016/j.vaccine.2007.01.010

123. Nguyen CT, Hong SH, Sin J-I, et al. Flagellin enhances tumor-specific CD8+ T cell immune responses through TLR5 stimulation in a therapeutic cancer vaccine model. Vaccine. 2013;31(37):3879-3887. doi:10.1016/j.vaccine.2013.06.054

124. Namvar A, Panahi HA, Agi E, Bolhassani A. Development of HPV16,18,31,45 E5 and E7 peptides-based vaccines predicted by immunoinformatics tools. Biotechnol Lett. 2020;42(3):403-418. doi:10.1007/s10529-020-02792-6

125. Kumar A, Yadav IS, Hussain S, Das BC, Bharadwaj M. Identification of immunotherapeutic epitope of E5 protein of human papillomavirus-16: an in silico approach. Biologicals. 2015;43(5):344-348. doi:10.1016/j.biologicals.2015.07.002

126. Cordeiro MN, Paolini F, Massa S, et al. Anti-tumor effects of genetic vaccines against HPV major oncogenes. Hum Vaccin Immunother. 2015;11(1):45-52. doi:10.4161/hv.34303

127. Testa JS, Philip R. Role of T-cell epitope-based vaccine in prophylactic and therapeutic applications. Future Virol. 2012;7(11):1077-1088. doi:10.2217/fvl.12.108

128. Alexander J, Sidney J, Southwood S, et al. Development of high potency universal DR-restricted helper epitopes by modification of high affinity DR-blocking peptides. Immunity. 1994;1(9):751-761. doi:10.1016/S1074-7613(94)80017-0

129. Muderspach L, Wilczynski S, Roman L, et al. A phase I trial of a human papillomavirus (HPV) peptide vaccine for women with high-grade cervical and vulvar intraepithelial neoplasia who are HPV 16 positive. Clin Cancer Res. 2000;6(9):3406-3416.

130. Ressing ME, van Driel WJ, Brandt RMP, et al. Detection of $\mathrm{T}$ helper responses, but not of human papillomavirus-specific cytotoxic T lymphocyte responses, after peptide vaccination of patients with cervical carcinoma. J Immunother. 2000;23(2):255-266. doi:10.1097/ 00002371-200003000-00010

131. van Driel WJ, Ressing ME, Kenter GG, et al. Vaccination with HPV16 peptides of patients with advanced cervical carcinoma: clinical evaluation of a phase I-II trial. Eur J Cancer. 1999;35(6):946-952. doi:10.1016/S0959-8049(99)00048-9

132. Jacoberger-Foissac C, Saliba H, Seguin C, et al. Optimization of peptide-based cancer vaccine compositions, by sequential screening, using versatile liposomal platform. Int J Pharm. 2019;562:342-350. doi:10.1016/j.ijpharm.2019.03.002

133. Hussein WM, Liu T-Y, Skwarczynski M, Toth I. Toll-like receptor agonists: a patent review (2011 - 2013$)$. Expert Opin Ther Pat. 2014;24 (4):453-470. doi:10.1517/13543776.2014.880691

134. Kawasaki T, Kawai T. Toll-Like receptor signaling pathways. Front Immunol. 2014;5:461. doi:10.3389/fimmu.2014.00461

135. Del Giudice G, Rappuoli R, Didierlaurent AM. Correlates of adjuvanticity: a review on adjuvants in licensed vaccines. Semin Immunol. 2018;39:14-21. doi:10.1016/j.smim.2018.05.001

136. Naud PS, Roteli-Martins CM, De Carvalho NS, et al. Sustained efficacy, immunogenicity, and safety of the HPV-16/18 AS04-adjuvanted vaccine. Hum Vaccin Immunother. 2014;10(8):2147-2162. doi:10.4161/hv.29532

137. López-Fauqued M, Zima J, Angelo M-G, Stegmann J-U. Results on exposure during pregnancy from a pregnancy registry for AS04-HPV-16/18 vaccine. Vaccine. 2017;35(40):5325-5330. doi:10.1016/j.vaccine.2017.08.042

138. Motavalli Khiavi F, Arashkia A, Golkar M, et al. A dual-type L2 11-88 peptide from HPV types $16 / 18$ formulated in Montanide ISA 720 induced strong and balanced Th1/Th2 immune responses, associated with high titers of broad spectrum cross-reactive antibodies in vaccinated mice. J Immunol Res. 2018;2018:9464186. doi:10.1155/2018/9464186

139. Bode C, Zhao G, Steinhagen F, Kinjo T, Klinman DM. CpG DNA as a vaccine adjuvant. Expert Rev Vaccines. 2011;10(4):499-511. doi:10.1586/erv.10.174

140. Khan MJ, Svedberg A, Singh AA, Ansari MS, Karim Z. Chapter 13 - use of nanostructured polymer in the delivery of drugs for cancer therapy. In: Swain SK, Jawaid M, editors. Nanostructured Polymer Composites for Biomedical Applications. Elsevier; 2019:261-276.

141. Embgenbroich M, Burgdorf S. Current concepts of antigen cross-presentation. Front Immunol. 2018;9:1643. doi:10.3389/fimmu.2018.01643

142. Azmi F, Ahmad Fuaad AAH, Skwarczynski M, Toth I. Recent progress in adjuvant discovery for peptide-based subunit vaccines. Hum Vaccin Immunother. 2014;10(3):778-796. doi:10.4161/hv.27332

143. Aucouturier J, Dupuis L, Ganne V. Adjuvants designed for veterinary and human vaccines. Vaccine. 2001;19(17-19):2666-2672. doi:10.1016/ S0264-410X(00)00498-9

144. Cuzzubbo S, Mangsbo S, Nagarajan D, et al. Cancer vaccines: adjuvant potency, importance of age, lifestyle, and treatments. Front Immunol. 2020;11:615240. doi:10.3389/fimmu.2020.615240

145. Khong H, Overwijk WW. Adjuvants for peptide-based cancer vaccines. J Immunother Cancer. 2016;4(1):56. doi:10.1186/s40425-016-0160-y

146. Zhou Y, Banday AH, Hruby VJ, Cai M. Development of $N$-acetylated dipalmitoyl-S-glyceryl cysteine analogs as efficient TLR2/TLR6 agonists. Molecules. 2019;24(19):3512. doi:10.3390/molecules24193512

147. Moyle PM, Dai W, Liu T-Y, et al. Combined synthetic and recombinant techniques for the development of lipoprotein-based, self-adjuvanting vaccines targeting human papillomavirus type-16 associated tumors. Bioorganic Med Chem Lett. 2015;25(23):5570-5575. doi:10.1016/j. bmcl.2015.10.049

148. Hussein WM, Liu T-Y, Maruthayanar P, et al. Double conjugation strategy to incorporate lipid adjuvants into multiantigenic vaccines. Chem Sci. 2016;7(3):2308-2321. doi:10.1039/C5SC03859F

149. Hussein WM, Mukaida S, Liu TY, Toth I. Fluorinated lipids conjugated to peptide antigens do not induce immune responses against cervical cancer. Vaccin Res Open J. 2017;1(1):39-44.

150. Hussein WM, Mukaida S, Azmi F, et al. Comparison of fluorinated and nonfluorinated lipids in self-adjuvanting delivery systems for peptide-based vaccines. ACS Med Chem Lett. 2017;8(2):227-232. doi:10.1021/acsmedchemlett.6b00453

151. Mousavi T, Sattari Saravi S, Valadan R, et al. Different types of adjuvants in prophylactic and therapeutic human papillomavirus vaccines in laboratory animals: a systematic review. Arch Virol. 2020;165(2):263-284. doi:10.1007/s00705-019-04479-4 
152. Domingos-Pereira S, Decrausaz L, Derré L, et al. Intravaginal TLR agonists increase local vaccine-specific CD8 $\mathrm{T}$ cells and human papillomavirus-associated genital-tumor regression in mice. Mucosal Immunol. 2013;6(2):393-404. doi:10.1038/mi.2012.83

153. Wick DA, Martin SD, Nelson BH, Webb JR. Profound CD8+ T cell immunity elicited by sequential daily immunization with exogenous antigen plus the TLR3 agonist poly(I:C). Vaccine. 2011;29(5):984-993. doi:10.1016/j.vaccine.2010.11.036

154. Hayashi F, Smith KD, Ozinsky A, et al. The innate immune response to bacterial flagellin is mediated by Toll-like receptor 5. Nature. 2001;410 (6832):1099-1103. doi:10.1038/35074106

155. Smith KD, Andersen-Nissen E, Hayashi F, et al. Toll-like receptor 5 recognizes a conserved site on flagellin required for protofilament formation and bacterial motility. Nat Immunol. 2003;4(12):1247-1253. doi:10.1038/ni1011

156. Chen W, Jiang M, Yu W, et al. CpG-based nanovaccines for cancer immunotherapy. Int J Nanomedicine. 2021;16:5281-5299. doi:10.2147/IJN. S317626

157. Scheiermann J, Klinman DM. Clinical evaluation of CpG oligonucleotides as adjuvants for vaccines targeting infectious diseases and cancer. Vaccine. 2014;32(48):6377-6389. doi:10.1016/j.vaccine.2014.06.065

158. Chen Y-F, Lin C-W, Tsao Y-P, Chen S-L. Cytotoxic-T-lymphocyte human papillomavirus type 16 E5 peptide with CpG-oligodeoxynucleotide can eliminate tumor growth in C57BL/6 mice. J Virol. 2004;78(3):1333-1343. doi:10.1128/JVI.78.3.1333-1343.2004

159. Yang Y, Che Y, Zhao Y, Wang X. Prevention and treatment of cervical cancer by a single administration of human papillomavirus peptide vaccine with CpG oligodeoxynucleotides as an adjuvant in vivo. Int Immunopharmacol. 2019;69:279-288. doi:10.1016/j.intimp.2019.01.024

160. Marasini N, Giddam AK, Khalil ZG, et al. Double adjuvanting strategy for peptide-based vaccines: trimethyl chitosan nanoparticles for lipopeptide delivery. Nanomedicine. 2016;11(24):3223-3235. doi:10.2217/nnm-2016-0291

161. Pati R, Shevtsov M, Sonawane A. Nanoparticle vaccines against infectious diseases. Front Immunol. $2018 ; 9: 2224$.

162. Zhao L, Seth A, Wibowo N, et al. Nanoparticle vaccines. Vaccine. 2014;32(3):327-337.

163. Ma W, Chen M, Kaushal S, et al. PLGA nanoparticle-mediated delivery of tumor antigenic peptides elicits effective immune responses. Int J Nanomedicine. 2012;7:1475-1487.

164. Demento SL, Siefert AL, Bandyopadhyay A, Sharp FA, Fahmy TM. Pathogen-associated molecular patterns on biomaterials: a paradigm for engineering new vaccines. Trends Biotechnol. 2011;29(6):294-306.

165. Zhao G, Chandrudu S, Skwarczynski M, Toth I. The application of self-assembled nanostructures in peptide-based subunit vaccine development. Eur Polym J. 2017;93:670-681.

166. Boles MA, Ling D, Hyeon T, Talapin DV. The surface science of nanocrystals. Nat Mater. 2016;15(2):141-153.

167. Choudhary S, Kusum Devi V. Potential of nanotechnology as a delivery platform against tuberculosis: current research review. $J$ Control Release. 2015;202:65-75.

168. Skwarczynski M, Zhao G, Boer JC, et al. Poly(amino acids) as a potent self-adjuvanting delivery system for peptide-based nanovaccines. Sci Adv. 2020;6(5):eaax2285.

169. Mir M, Ahmed N, Rehman AU. Recent applications of PLGA based nanostructures in drug delivery. Colloids Surf B. 2017;159:217-231.

170. Win KY, Feng SS. Effects of particle size and surface coating on cellular uptake of polymeric nanoparticles for oral delivery of anticancer drugs. Biomaterials. 2005;26(15):2713-2722.

171. Nevagi RJ, Skwarczynski M, Toth I. Polymers for subunit vaccine delivery. Eur Polym J. 2019;114:397-410.

172. Mehdi K, Mohsen M, Naser Mohammadpour D, Mohsen M, Alireza M. Nanoparticles and vaccine development. Pharm Nanotechnol. 2020;8 (1):6-21

173. Malik A, Gupta M, Gupta V, Gogoi H, Bhatnagar R. Novel application of trimethyl chitosan as an adjuvant in vaccine delivery. Int J Nanomedicine. 2018;13:7959-7970.

174. Martău GA, Mihai M, Vodnar DC. The use of chitosan, alginate, and pectin in the biomedical and food sector-biocompatibility, bioadhesiveness, and biodegradability. Polymers. 2019;11:11.

175. Zhao L, Skwarczynski M, Toth I. Polyelectrolyte-based platforms for the delivery of peptides and proteins. ACS Biomater Sci Eng. 2019;5 (10):4937-4950.

176. Sun B, Yu S, Zhao D, et al. Polysaccharides as vaccine adjuvants. Vaccine. 2018;36(35):5226-5234

177. Li X, Min M, Du N, et al. Chitin, chitosan, and glycated chitosan regulate immune responses: the novel adjuvants for cancer vaccine. Clin Dev Immunol. 2013;2013:387023.

178. Silva AL, Soema PC, Slutter B, Ossendorp F, Jiskoot W. PLGA particulate delivery systems for subunit vaccines: linking particle properties to immunogenicity. Hum Vaccin Immunother. 2016;12(4):1056-1069.

179. Makadia HK, Siegel SJ. Poly lactic-co-glycolic acid (PLGA) as biodegradable controlled drug delivery carrier. Polymers. $2011 ; 3(3): 1377-1397$.

180. Gutjahr A, Phelip C, Coolen AL, et al. Biodegradable polymeric nanoparticles-based vaccine adjuvants for lymph nodes targeting. Vaccines. 2016;4(4):34.

181. Marasini N, Khalil ZG, Giddam AK, et al. Lipid core peptide/poly(lactic-co-glycolic acid) as a highly potent intranasal vaccine delivery system against Group A streptococcus. Int J Pharm. 2016;513(1):410-420.

182. Ghassemi AH, van Steenbergen MJ, Talsma H, et al. Preparation and characterization of protein loaded microspheres based on a hydroxylated aliphatic polyester, poly(lactic-co-hydroxymethyl glycolic acid). J Control Release. 2009;138(1):57-63.

183. Zhang Q, Huang W, Yuan M, et al. Employing ATP as a new adjuvant promotes the induction of robust antitumor cellular immunity by a PLGA nanoparticle vaccine. ACS Appl Mater Interfaces. 2020;12(49):54399-54414.

184. Rahimian S, Fransen MF, Kleinovink JW, et al. Polymeric nanoparticles for co-delivery of synthetic long peptide antigen and poly IC as therapeutic cancer vaccine formulation. J Control Release. 2015;203:16-22.

185. Hilgers LAT, Ghenne L, Nicolas I, et al. Alkyl-polyacrylate esters are strong mucosal adjuvants. Vaccine. 2000;18(28):3319-3325.

186. Skwarczynski M, Zaman M, Urbani CN, et al. Polyacrylate dendrimer nanoparticles: a self-adjuvanting vaccine delivery system. Angew Chem Int Ed. 2010;49(33):5742-5745.

187. Liu TY, Hussein WM, Giddam AK, et al. Polyacrylate-based delivery system for self-adjuvanting anticancer peptide vaccine. $J$ Med Chem. 2015;58(2):888-896.

188. Liu TY, Giddam AK, Hussein WM, et al. Self-adjuvanting therapeutic peptide-based vaccine induce CD8+ cytotoxic T lymphocyte responses in a murine human papillomavirus tumor model. Curr Drug Deliv. 2015;12(1):3-8. 
189. Hussein WM, Choi PM, Zhang C, et al. Investigating the affinity of poly tert-butyl acrylate toward toll-like receptor 2. AIMS Allergy Immunol. 2018;2(3):141-147.

190. Khongkow MLT, Bartlett S, Hussein WM, et al. Liposomal formulation of polyacrylate-peptide conjugate as a new vaccine candidate against cervical cancer. Prec Namomed. 2018;1(3):183-193.

191. Truong HH,; Hussein WM, Liu T, et al. Self-adjuvanting peptide vaccines against cervical cancer. Vaccin Res Open J. 2019;1(1):81-89.

192. Rad-Malekshahi M, Fransen MF, Krawczyk M, et al. Self-assembling peptide epitopes as novel platform for anticancer vaccination. Mol Pharm. 2017;14(5):1482-1493.

193. Ma X, Wang Y, Zhao T, et al. Ultra-pH-sensitive nanoprobe library with broad $\mathrm{pH}$ tunability and fluorescence emissions. $J$ Am Chem Soc. 2014;136(31):11085-11092.

194. Luo M, Wang H, Wang Z, et al. A STING-activating nanovaccine for cancer immunotherapy. Nat Nanotechnol. 2017;12(7):648-654.

195. Luo M, Liu Z, Zhang X, et al. Synergistic STING activation by PC7A nanovaccine and ionizing radiation improves cancer immunotherapy. J Control Release. 2019;300:154-160.

196. Abu Lila AS, Ishida T. Liposomal delivery systems: design optimization and current applications. Biol Pharm Bull. 2017;40(1):1-10.

197. Nisini R, Poerio N, Mariotti S, De Santis F, Fraziano M. The multirole of liposomes in therapy and prevention of infectious diseases. Front Immunol. 2018;9:155.

198. Daraee H, Etemadi A, Kouhi M, Alimirzalu S, Akbarzadeh A. Application of liposomes in medicine and drug delivery. Artif Cells Nanomed Biotechnol. 2016;44(1):381-391.

199. Khairunnisa Abdul G, Ashwini Kumar G, Mehfuz Z, Mariusz S, Istvan T. Liposomes as nanovaccine delivery systems. Curr Top Med Chem. 2014;14(9):1194-1208.

200. Giddam AK, Zaman M, Skwarczynski M, Toth I. Liposome-based delivery system for vaccine candidates: constructing an effective formulation. Nanomedicine. 2012;7(12):1877-1893.

201. Yan W, Chen W, Huang L. Mechanism of adjuvant activity of cationic liposome: phosphorylation of a MAP kinase, ERK and induction of chemokines. Mol Immunol. 2007;44(15):3672-3681.

202. Chen W, Yan W, Huang L. A simple but effective cancer vaccine consisting of an antigen and a cationic lipid. Cancer Immunol Immunother. 2008;57(4):517-530.

203. Chen W, Huang L. Induction of cytotoxic T-lymphocytes and antitumor activity by a liposomal lipopeptide vaccine. Mol Pharm. 2008;5 (3):464-471.

204. Vasievich EA, Chen W, Huang L. Enantiospecific adjuvant activity of cationic lipid DOTAP in cancer vaccine. Cancer Immunol Immunother. 2011;60(5):629-638.

205. He X, Zhou S, Quinn B, et al. HPV-associated tumor eradication by vaccination with synthetic short peptides and particle-forming liposomes. Small. 2021;17(11):2007165.

206. Daftarian PM, Mansour M, Pohajdak B, et al. Rejection of large HPV-16 expressing tumors in aged mice by a single immunization of VacciMax encapsulated CTL/T helper peptides. J Transl Med. 2007;5:26.

207. Weir GM, Hrytsenko O, Quinton T, et al. Anti-PD-1 increases the clonality and activity of tumor infiltrating antigen specific T cells induced by a potent immune therapy consisting of vaccine and metronomic cyclophosphamide. J Immunother Cancer. 2016;4:68.

208. Weir GM, Hrytsenko O, Stanford MM, et al. Metronomic cyclophosphamide enhances HPV16E7 peptide vaccine induced antigen-specific and cytotoxic T-cell mediated antitumor immune response. OncoImmunology. 2014;3(8):e953407.

209. Arevalo MT, Wong TM, Ross TM. Expression and purification of virus-like particles for vaccination. J Vis Exp. 2016;112:e54041.

210. Mohsen MO, Speiser DE, Knuth A, Bachmann MF. Virus-like particles for vaccination against cancer. Wiley Interdiscip Rev Nanomed Nanobiotechnol. 2020;12(1):e1579.

211. Nooraei S, Bahrulolum H, Hoseini ZS, et al. Virus-like particles: preparation, immunogenicity and their roles as nanovaccines and drug nanocarriers. J Nanobiotechnol. 2021;19(1):59.

212. Müller M, Zhou J, Reed TD, et al. Chimeric papillomavirus-like particles. Virology. 1997;234(1):93-111.

213. Schäfer K, Müller M, Faath S, et al. Immune response to human papillomavirus 16 L1E7 chimeric virus-like particles: induction of cytotoxic T cells and specific tumor protection. Int J Cancer. 1999;81(6):881-888.

214. Kaufmann AM, Nieland JD, Jochmus I, et al. Vaccination trial with HPV16 L1E7 chimeric virus-like particles in women suffering from high grade cervical intraepithelial neoplasia (CIN 2/3). Int J Cancer. 2007;121(12):2794-2800.

215. Freyschmidt EJ, Alonso A, Hartmann G, Gissmann L. Activation of dendritic cells and induction of T cell responses by HPV 16 L1/E7 chimeric virus-like particles are enhanced by CpG ODN or sorbitol. Antivir Ther. 2004;9(4):479-489.

216. Monroy-García A, Gómez-Lim MA, Weiss-Steider B, et al. Immunization with an HPV-16 L1-based chimeric virus-like particle containing HPV-16 E6 and E7 epitopes elicits long-lasting prophylactic and therapeutic efficacy in an HPV-16 tumor mice model. Arch Virol. 2014;159 (2):291-305.

217. Jemon K, Young V, Wilson M, et al. An enhanced heterologous virus-like particle for human papillomavirus type 16 tumour immunotherapy. PLoS One. 2013;8(6):e66866.

218. Martin Caballero J, Garzón A, González-Cintado L, et al. Chimeric infectious bursal disease virus-like particles as potent vaccines for eradication of established HPV-16 E7-dependent tumors. PLoS One. 2013;7(12):e52976.

219. Chu X, Yang L, Long Q, et al. Chimeric HBcAg virus-like particles presenting a HPV 16 E7 epitope significantly suppressed tumor progression through preventive or therapeutic immunization in a TC-1-grafted mouse model. Int J Nanomedicine. 2016;11:2417-2429.

220. Gomes AC, Flace A, Saudan P, et al. Adjusted particle size eliminates the need of linkage of antigen and adjuvants for appropriated T cell responses in virus-like particle-based vaccines. Front Immunol. 2017;8:226.

221. Shi Y, Liu CH, Roberts AI, et al. Granulocyte-macrophage colony-stimulating factor (GM-CSF) and T-cell responses: what we do and don't know. Cell Res. 2006;16(2):126-133.

222. Simmons AD, Li B, Gonzalez-Edick M, et al. GM-CSF-secreting cancer immunotherapies: preclinical analysis of the mechanism of action. Cancer Immunol Immunother. 2007;56(10):1653-1665.

223. Tang J, Yin R, Tian Y, et al. A novel self-assembled nanoparticle vaccine with HIV-1 Tat49-57/HPV16 E749-57 fusion peptide and GM-CSF DNA elicits potent and prolonged CD8+ T cell-dependent anti-tumor immunity in mice. Vaccine. 2012;30(6):1071-1082. 
224. Ressing ME, van Driel WJ, Celis E, et al. Occasional memory cytotoxic T-cell responses of patients with human papillomavirus type 16positive cervical lesions against a human leukocyte antigen-A *0201-restricted E7-encoded epitope. Cancer Res. 1996;56(3):582-588.

225. Kenter GG, Welters MJ, Valentijn AR, et al. Phase I immunotherapeutic trial with long peptides spanning the E6 and E7 sequences of high-risk human papillomavirus 16 in end-stage cervical cancer patients shows low toxicity and robust immunogenicity. Clin Cancer Res. 2008;14 (1):169-177.

226. Kenter GG, Welters MJ, Valentijn AR, et al. Vaccination against HPV-16 oncoproteins for vulvar intraepithelial neoplasia. $N$ Engl $J$ Med. 2009;361(19):1838-1847.

227. de Vos van Steenwijk PJ, Ramwadhdoebe TH, Löwik MJG, et al. A placebo-controlled randomized HPV16 synthetic long-peptide vaccination study in women with high-grade cervical squamous intraepithelial lesions. Cancer Immunol Immunother. 2012;61(9):1485-1492.

228. van Poelgeest MIE, Welters MJP, van Esch EMG, et al. HPV16 synthetic long peptide (HPV16-SLP) vaccination therapy of patients with advanced or recurrent HPV16-induced gynecological carcinoma, a phase II trial. J Transl Med. 2013;11:88.

229. de Vos van Steenwijk PJ, van Poelgeest MIE, Ramwadhdoebe TH, et al. The long-term immune response after HPV16 peptide vaccination in women with low-grade pre-malignant disorders of the uterine cervix: a placebo-controlled phase II study. Cancer Immunol Immunother. 2014;63(2):147-160.

230. Hasegawa K, Ikeda Y, Kunugi Y, et al. Phase I study of multiple epitope peptide vaccination in patients with recurrent or persistent cervical cancer. J Immunother. 2018;41(4):201-207.

231. Ohno S, Okuyama R, Aruga A, Sugiyama H, Yamamoto M. Phase I trial of Wilms' tumor 1 (WT1) peptide vaccine with GM-CSF or CPG in patients with solid malignancy. Anticancer Res. 2012;32(6):2263.

232. Oka Y, Tsuboi A, Oji Y, Kawase I, Sugiyama H. WT1 peptide vaccine for the treatment of cancer. Curr Opin Immunol. 2008;20(2):211-220.

233. Miyatake T, Ueda Y, Morimoto A, et al. WT1 peptide immunotherapy for gynecologic malignancies resistant to conventional therapies: a phase II trial. J Cancer Res Clin Oncol. 2013;139(3):457-463.

234. Reuschenbach M, Rafiyan M, Pauligk C, et al. Phase I/IIa trial targeting p16INK4a by peptide vaccination in patients with human papillomavirus-associated cancer. J Clin Oncol. 2015;33(15_suppl):e14030-e14030.

235. Wang X, Coleman HN, Nagarajan U, Spencer HJ, Nakagawa M. Candida skin test reagent as a novel adjuvant for a human papillomavirus peptide-based therapeutic vaccine. Vaccine. 2013;31(49):5806-5813.

236. Coleman HN, Greenfield WW, Stratton SL, et al. Human papillomavirus type 16 viral load is decreased following a therapeutic vaccination. Cancer Immunol Immunother. 2016;65(5):563-573.

237. Nakagawa M, Coleman HN, Wang X, et al. IL-12 secretion by Langerhans cells stimulated with Candida skin test reagent is mediated by dectin-1 in some healthy individuals. Cytokine. 2014;65(2):202-209.

238. Greenfield WW, Stratton SL, Myrick RS, et al. A phase I dose-escalation clinical trial of a peptide-based human papillomavirus therapeutic vaccine with Candida skin test reagent as a novel vaccine adjuvant for treating women with biopsy-proven cervical intraepithelial neoplasia $2 / 3$. Oncoimmunology. 2015;4(10):e1031439-e1031439.

239. Smalley Rumfield C, Pellom ST, Morillon Ii YM, Schlom J, Jochems C. Immunomodulation to enhance the efficacy of an HPV therapeutic vaccine. J Immunother Cancer. 2020;8(1):e000612.

240. Brewer KD, Weir GM, Dude I, et al. Unique depot formed by an oil based vaccine facilitates active antigen uptake and provides effective tumour control. J Biomed Sci. 2018;25(1):7.

241. Wang C, Dickie J, Sutavani RV, et al. Targeting head and neck cancer by vaccination. Front Immunol. 2018;9:830.

242. Domingos-Pereira S, Galliverti G, Hanahan D, Nardelli-Haefliger D. Carboplatin/paclitaxel, E7-vaccination and intravaginal CpG as tri-therapy towards efficient regression of genital HPV16 tumors. J Immunother Cancer. 2019;7(1):122.

243. Welters Marij J, van der Sluis Tetje C, van Meir H, et al. Vaccination during myeloid cell depletion by cancer chemotherapy fosters robust T cell responses. Sci Transl Med. 2016;8(334):334ra352-334ra352.

244. Shibata T, Lieblong BJ, Sasagawa T, Nakagawa M. The promise of combining cancer vaccine and checkpoint blockade for treating HPV-related cancer. Cancer Treat Rev. 2019;78:8-16.

245. Massarelli E, William W, Johnson F, et al. Combining immune checkpoint blockade and tumor-specific vaccine for patients with incurable human papillomavirus 16-related cancer: a Phase 2 clinical trial. JAMA Oncol. 2019;5(1):67-73.

International Journal of Nanomedicine

\section{Publish your work in this journal}

The International Journal of Nanomedicine is an international, peer-reviewed journal focusing on the application of nanotechnology in diagnostics, therapeutics, and drug delivery systems throughout the biomedical field. This journal is indexed on PubMed Central, MedLine, CAS, SciSearch ${ }^{\circledR}$, Current Contents ${ }^{\mathbb{R}} /$ Clinical Medicine, Journal Citation Reports/Science Edition, EMBase, Scopus and the Elsevier Bibliographic databases. The manuscript management system is completely online and includes a very quick and fair peer-review system, which is all easy to use. Visit http:// www.dovepress.com/testimonials.php to read real quotes from published authors.

Submit your manuscript here: https://www.dovepress.com/international-journal-of-nanomedicine-journal 